\title{
Downscaling AMSR-2 Soil Moisture Data With Geographically Weighted Area-to-Area Regression Kriging
}

\author{
Yan Jin ${ }^{(1)}$, Yong Ge, Member, IEEE, Jianghao Wang, Yuehong Chen ${ }^{(1)}$, \\ Gerard B. M. Heuvelink, and Peter M. Atkinson ${ }^{(1)}$
}

\begin{abstract}
Soil moisture (SM) plays an important role in the land surface energy balance and water cycle. Microwave remote sensing has been applied widely to estimate SM. However, the application of such data is generally restricted because of their coarse spatial resolution. Downscaling methods have been applied to predict fine-resolution SM from original data with coarse spatial resolution. Commonly, SM is highly spatially variable and, consequently, such local spatial heterogeneity should be considered in a downscaling process. Here, a hybrid geostatistical approach, which integrates geographically weighted regression and area-to-area kriging, is proposed for downscaling microwave SM products. The proposed geographically weighted area-to-area regression kriging (GWATARK) method combines fine-spatial-resolution optical remote sensing data and coarse-spatial-resolution passive microwave remote sensing data, because the combination of both information sources has great potential for mapping fine-spatial-resolution near-surface SM. The GWATARK method was evaluated by producing downscaled SM at $1-\mathrm{km}$ resolution from the $25-\mathrm{km}$-resolution daily AMSR-2 SM product. Comparison of the downscaled predictions from the GWATARK method and two benchmark methods on three sets of covariates with in situ observations showed that the GWATARK method is more accurate than the two benchmarks. On average, the root-mean-square error value decreased by $20 \%$. The use of additional covariates further increased the accuracy of the downscaled predictions, particularly when using topographycorrected land surface temperature and vegetation-temperature condition index covariates.
\end{abstract}

Manuscript received August 8, 2017; revised October 25, 2017 and November 15, 2017; accepted November 17, 2017. This work was supported by two Key Programs of the National Natural Science Foundation of China under Grant 41531174 and Grant 41531179. (Corresponding authors: Yong Ge; Jianghao Wang.)

Y. Jin, Y. Ge, and J. Wang are with the State Key Laboratory of Resources and Environmental Information Systems, Institute of Geographic Sciences and Natural Resources Research, Chinese Academy of Sciences, Beijing 100101, China, and also with the College of Resources and Environment, University of Chinese Academy of Sciences, Beijing 100049, China (e-mail: jiny@1reis.ac.cn; gey@1reis.ac.cn; wangjh@1reis.ac.cn).

Y. Chen is with the School of Earth Sciences and Engineering, Hohai University, Nanjing 210098, China (e-mail: chenyh@1reis.ac.cn).

G. B. M. Heuvelink is with the Soil Geography and Landscape Group, Wageningen University, 6700 AA Wageningen, The Netherlands (e-mail: gerard.heuvelink@wur.nl).

P. M. Atkinson is with the Faculty of Science and Technology, Lancaster University, Lancaster LA1 4YR, U.K., with the School of Natural and Built Environment, Queen's University Belfast, Belfast BT7 1NN, U.K., and also with Geography and Environment, University of Southampton, Southampton S017 1BJ, U.K. (e-mail: pma@lancaster.ac.uk).

Color versions of one or more of the figures in this paper are available online at http://ieeexplore.ieee.org.

Digital Object Identifier 10.1109/TGRS.2017.2778420
Index Terms-Covariance matrices, geospatial analysis, highresolution imaging, remote sensing, spatial resolution.

\section{INTRODUCTION}

OIL moisture (SM) is an important land surface parameter $\checkmark$ used in the modeling of ecohydrological processes and for understanding the behavior and functioning of ecosystems [1], [2]. Although traditional measurement methods (i.e., gravimetric), wireless sensor network (WSN) dynamic observations [3], and cosmic-ray neutron dynamic observations [4] can provide SM information with high accuracy, and at multiple depths, the application of such methods across large areas is impractical. At regional, continental, and global scales, remote sensing of surface SM is considered the optimum solution. In particular, microwave remote sensing has been applied widely to the monitoring of SM because of its high sensitivity to SM and its robustness to atmospheric conditions [5].

There are various active (e.g., the Advanced Synthetic Aperture Radar and Advanced Scatterometer) and passive [e.g., the Advanced Microwave Scanning Radiometer for the Earth Observing System (AMSR-E), Advanced Microwave Scanning Radiometer 2 (AMSR-2), and Soil Moisture and Ocean Salinity instrument] microwave sensors. Compared with active sensing, which requires detailed background information such as terrain and soil texture, passive microwave remote sensing is better suited to capturing the spatio-temporal variation of SM over large areas. Most passive sensors provide SM products with fine temporal resolution of 1-3 d and coarse spatial resolution of about 25-50 km. Launched in 2015, the SM active-passive sensor provides different resolutions, including a finer spatial resolution of $9 \mathrm{~km}$. However, the spatial resolutions of all these sensors are too coarse to be useful in catchment-based hydroecological modeling, as required for forecasting floods and droughts [6]. Therefore, it is necessary to increase the spatial resolution of passive microwave SM products.

Several methods have been developed to downscale passive microwave remote sensing products: general statistical methods [7], machine learning methods [8], process-based methods [9], fractal methods [10], geostatistical methods [11], and hybrid methods [12]. Recently, Peng et al. [13] systematically reviewed the existing methods used for downscaling satellite remotely sensed SM. To downscale SM, most of 
the above methods commonly combine ancillary information with passive microwave remote sensing data [14]-[16]. For example, direct optical remote sensing products with fine spatial resolution, such as land surface temperature (LST) and normalized difference vegetation index (NDVI) [17]-[19], and indirect products, such as soil evaporative efficiency [20], [21] and temperature-vegetation indices [22], have commonly been employed.

The most widely used general statistical downscaling methods, e.g., quadratic regression model (QRM) [15], are easy to apply; however, such methods focus on the parameter space and they ignore spatial aspects. Kim and Hogue [22] indicated that QRM might not be optimal in terms of downscaling accuracy. Recently, with consideration of the spatial correlation among ecohydrological variables, geostatistical methods have advanced [23], [24] and they have been increasingly applied to downscaling SM [25], [26]. To resolve the change of support problem (COSP), which is one of the principal challenges in a downscaling process, two highperforming downscaling methods have been developed: areato-point regression kriging (ATPRK) [27] and area-to-area regression kriging (ATARK) [28]. These methods combine regression kriging [29] with area-to-point or area-to-area kriging (ATPK/ATAK) [30]-[32]. Many studies have demonstrated the downscaling potential of ATPRK and ATARK (see [33]-[35]); however, there have been few applications to remote sensing [36], [37] and, as far as we are aware, none to the downscaling of SM data.

The global approach used typically in ATPRK and ATARK might be inadequate to capture the local behavior of highly spatially heterogeneous SM [38]. A more suitable model would allow for nonstationarity in the model parameters. Geographically weighted regression (GWR) [39] is a wellestablished, nonstationary regression model that has been applied to SM data [19]; however, hybrid methods combining GWR and kriging (e.g., GWR-kriging [40]) are rare. To tackle the problem of local heterogeneity, this paper describes the integration of GWR and ATAK for downscaling SM using fine-spatial-resolution optical image covariates [e.g., Moderate Resolution Imaging Spectroradiometer (MODIS) products]. The proposed geographically weighted area-to-area regression kriging (GWATARK) method retains the advantages of ATARK, while capturing the spatial nonstationary relationships between dependent and ancillary variables. To validate this method, a real-world application was implemented by downscaling, from 25 to $1 \mathrm{~km}$, the AMSR-2 SM product [41] of the Heihe Water Allied Telemetry Experimental Research (HiWATER) [42] experiment.

The structure of the remainder of this paper is as follows. Section II describes the proposed GWATARK downscaling approach. Section III presents the case study and it provides the experimental results used for the validation, which are discussed in Section IV. Section V presents the conclusion.

\section{Methods}

\section{A. General Formulation}

Assume that vector $Z(O)=\left\{Z\left(O_{i}\right), i=1,2, \ldots, n\right\}$ represents the coarse SM observations at $n$ spatially distributed pixels $O_{i}=\left(U_{i}, V_{i}\right)(i=1,2, \ldots, n)$ and that $Z(o)=\left\{Z\left(o_{j}\right), j=1,2, \ldots, n F^{2}\right\}$ represents the fine SM predictions at $n F^{2}$ spatial observation pixels $o_{j}=\left(u_{j}, v_{j}\right)(j=$ $\left.1,2, \ldots, n F^{2}\right)$. Here, $F$ is the ratio between the coarse- and fine-spatial resolutions, and $\left(U_{i}, V_{i}\right)$ and $\left(u_{j}, v_{j}\right)$ are the geographic positions (latitudes and longitudes) of the centers of the coarse- and fine-resolution pixels, respectively. The proposed downscaling approach contains two phases: a regression model that predicts the spatial trend of SM at fine resolution, and an interpolation model to downscale the regression residuals in order to obtain fine-resolution predictions. The general form of the GWATARK prediction, therefore, comprises a trend component and a residual component

$$
Z\left(o_{j}\right)=m\left(o_{j}\right)+R\left(o_{j}\right)
$$

where $m\left(o_{j}\right)$ is the deterministic part estimated by GWR and $R\left(o_{j}\right)$ is the regression residual interpolated with ATAK. Here, $R\left(o_{j}\right)$ is assumed normally distributed with zero mean, spatially constant variance, and spatial correlation that is a function only of separation distance.

\section{B. GWR to Estimate the Spatial Trend}

Benefitting from the fine-spatial-resolution information of the covariates, the regression step in GWATARK aims to establish the trend model of the fine-resolution SM using fineresolution covariates. Let $x_{k}\left(O_{i}\right)(k=1, \ldots, p)$ be the value of the $k$ th covariate at coarse pixel $O_{i}$, and $\boldsymbol{\beta}\left(U_{i}, V_{i}\right)=$ $\left\{\beta_{l}\left(U_{i}, V_{i}\right), l=0,1, \ldots, p\right\}$ be the regression coefficients with geographic position $\left(U_{i}, V_{i}\right)$. The corresponding fineresolution data and parameters are $x_{k}\left(o_{j}\right)$ for pixel $o_{j}$ and $\boldsymbol{\beta}\left(u_{j}, v_{j}\right)=\left\{\beta_{l}\left(u_{j}, v_{j}\right), l=0,1, \ldots, p\right\}$ for position $\left(u_{j}, v_{j}\right)$, with $\beta_{0}(\cdot, \cdot)$ as the intercept.

The relationship between the SM and the covariates at fine resolution is modeled by linear regression using the GWR model

$$
m\left(o_{j}\right)=\beta_{0}\left(u_{j}, v_{j}\right)+\sum_{k=1}^{p} \beta_{k}\left(u_{j}, v_{j}\right) \cdot x_{k}\left(o_{j}\right) .
$$

We impose that $\boldsymbol{\beta}\left(u_{j}, v_{j}\right)$ is equal to $\boldsymbol{\beta}\left(U_{i}, V_{i}\right)$ when pixel $o_{j}$ is located in large pixel $O_{i}$ (i.e., we do not allow the $\boldsymbol{\beta}\left(u_{j}, v_{j}\right)$ coefficients to vary within large pixels). This restriction is acceptable given that the large pixels are still small compared with the extent of the study area. Recall that each large pixel corresponds to $F^{2}$ small pixels. Therefore, the sum of the GWR predictions at fine resolution within $O_{i}$ can be written as

$$
\begin{aligned}
\sum_{j=1, o_{j} \in O_{i}}^{F^{2}} m\left(o_{j}\right)= & \sum_{j=1, o_{j} \in O_{i}}^{F^{2}} \beta_{0}\left(u_{j}, v_{j}\right) \\
& +\sum_{j=1, o_{j} \in O_{i}}^{F^{2}} \sum_{k=1}^{p} \beta_{k}\left(u_{j}, v_{j}\right) \cdot x_{k}\left(o_{j}\right) .
\end{aligned}
$$

Acknowledging that coefficients are constant within large pixels and dividing by $F^{2}$ gives

$$
m\left(O_{i}\right)=\beta_{0}\left(U_{i}, V_{i}\right)+\sum_{k=1}^{p} \beta_{k}\left(U_{i}, V_{i}\right) \cdot x_{k}\left(O_{i}\right)
$$


where $m\left(O_{i}\right)$ is the average of $m\left(o_{j}\right)$ within $O_{i}$ and $x_{k}\left(O_{i}\right)$ is the average of $x_{k}\left(o_{j}\right)$ within $O_{i}$. It is evident that (3) yields (4) because the regression coefficients are constant within a large pixel; hence, it can be placed in front of the summation over the small pixels.

Equation (4) implies that the regression coefficients could be fit using the coarse-resolution data (SM data from AMSR-2 and upscaled covariates), whereas (2) shows that the fit model could be applied at fine spatial resolution. The spatially varying regression coefficients $\boldsymbol{\beta}\left(U_{i}, V_{i}\right)$ at different positions are estimated using the weighted least-squares method in basic GWR, in which one of the important steps is to choose a distance-decay function to represent the strength of the connectivity between pixels. Here, the common Gaussian distance-decay function is selected. Furthermore, the GWR with a locally compensated ridge term [43] is employed to address local collinearity.

In practice, the estimation of the regression coefficients and of the trend from the available data introduces an estimation error. Accounting for this and turning to vector notation, we write $\hat{m}\left(O_{i}\right)=\boldsymbol{x}\left(O_{i}\right)^{T} \cdot \hat{\boldsymbol{\beta}}\left(U_{i}, V_{i}\right)$. The estimation error variance is given by

$$
\begin{aligned}
\hat{\sigma}_{\mathrm{GWR}}^{2}\left(O_{i}\right) & =\operatorname{Var}\left\{\hat{m}\left(O_{i}\right)-m\left(O_{i}\right)\right\} \\
& =\operatorname{Var}\left\{\boldsymbol{x}\left(O_{i}\right)^{T} \cdot \hat{\boldsymbol{\beta}}\left(U_{i}, V_{i}\right)-m\left(O_{i}\right)\right\} \\
& =\hat{\sigma}^{2} \cdot H\left(O_{i}\right)
\end{aligned}
$$

in which

$$
\begin{aligned}
& H\left(O_{i}\right)=\boldsymbol{x}\left(O_{i}\right)^{T} \cdot\left[X^{T} W\left(O_{i}\right) X\right]^{-1} \cdot X^{T} \cdot W\left(O_{i}\right) \\
& \cdot W\left(O_{i}\right)^{T} \cdot X \cdot\left[X^{T} W\left(O_{i}\right) X\right]^{-T} \cdot \boldsymbol{x}\left(O_{i}\right)
\end{aligned}
$$

and the residual variance is

$$
\hat{\sigma}^{2}=\mathrm{RSS} / \mathrm{EDF}
$$

where $W\left(O_{i}\right)$ is the weight matrix at location $O_{i}, X$ is the design matrix, RSS is the residual sum of squares, and EDF is the efficient degrees of freedom. For details, we refer the reader to [44].

\section{ATAK for Downscaling the Residuals}

If the regression models were perfect and if there were no observation errors in the coarse-resolution SM, then the regression coefficients would be estimated without error and the stochastic residual $R$ would be 0 . This means that regression (2) would perform downscaling without error. However, in practice, this is never the case and regression residuals do occur. In the proposed method, their spatial variation is modeled using geostatistical techniques. If the residuals have spatial structure, they can be interpolated to reduce the final residuals of the integrated GWATARK model.

The residuals at coarse resolution were computed by subtracting the upscaled trend from the observed SM at each large pixel as follows:

$$
R\left(O_{i}\right)=Z\left(O_{i}\right)-\left[\hat{\beta}_{0}\left(U_{i}, V_{i}\right)+\sum_{k=1}^{p} \hat{\beta}_{k}\left(U_{i}, V_{i}\right) \cdot x_{k}\left(O_{i}\right)\right] \text {. }
$$

Next, ATAK was employed to downscale the regression residuals to obtain predictions of the residuals at fine resolution. For a given pixel $o_{j}$, the residual SM is predicted as a linear combination of the residuals $R\left(O_{h}\right)(h=1, \ldots, m)$ in $m$ coarse neighboring pixels

$$
\hat{R}\left(o_{j}\right)=\sum_{h=1}^{m} \lambda_{h j} \cdot \hat{R}\left(O_{h}\right)
$$

where $\lambda_{h j}$ represents the ATAK weights. The weights are estimated by minimizing the prediction error variance, while preserving unbiasedness. The corresponding kriging system can be written as

$$
\left\{\begin{array}{l}
\sum_{i=1}^{m} \lambda_{i j} \bar{C}\left(O_{h}, O_{i}\right)+\mu\left(o_{j}\right)=\bar{C}\left(O_{h}, o_{j}\right), \quad h=1,2 \ldots m \\
\sum_{i=1}^{m} \lambda_{i j}=1
\end{array}\right.
$$

where $\bar{C}\left(O_{h}, O_{i}\right)$ and $\bar{C}\left(O_{h}, o_{j}\right)$ are block-to-block covariance terms and $\mu\left(o_{j}\right)$ are Lagrange multipliers. The covariance terms are derived from the point support semivariogram, which is derived from the coarse (block) observations using a deconvolution procedure. For further details, the reader is referred to [45]. The ATAK prediction error variance for the residual averaged over the fine pixel is computed as

$$
\begin{aligned}
\operatorname{Var}\left\{\hat{R}\left(o_{j}\right)-R\left(o_{j}\right)\right\} & =\sigma_{\mathrm{ATAK}}^{2}\left(o_{j}\right) \\
& =\bar{C}\left(o_{j}, o_{j}\right)-\sum_{h=1}^{m} \lambda_{h j} \bar{C}\left(O_{h}, o_{j}\right)-\mu\left(o_{j}\right) .
\end{aligned}
$$

\section{GWATARK Method}

By combining the estimated trend and downscaled prediction of residuals using (2) and (9), the general form of the GWATARK (1) predictor can be written as

$$
\begin{aligned}
\hat{Z}\left(o_{j}\right) \\
=\hat{m}\left(o_{j}\right)+\hat{R}\left(o_{j}\right) \\
=\hat{\beta}_{0}\left(u_{j}, v_{j}\right)+\sum_{k=1}^{p} \hat{\beta}_{k}\left(u_{j}, v_{j}\right) \cdot x_{k}\left(o_{j}\right)+\sum_{h=1}^{m} \lambda_{h j} \\
\\
\quad\left\{Z\left(O_{h}\right)-\left[\hat{\beta}_{0}\left(U_{h}, V_{h}\right)+\sum_{k=1}^{p} \hat{\beta}_{k}\left(U_{h}, V_{h}\right) \cdot x_{k}\left(O_{h}\right)\right]\right\} .
\end{aligned}
$$

The corresponding prediction error variance involves two parts, analogous to the GWRK prediction error variance in [40]: the first part represents the trend estimation error and the second part reflects the residual interpolation variance. The GWATARK prediction error variance at $o_{j}$ is, thus, given by

$$
\begin{aligned}
& \hat{\sigma}_{\text {GWATARK }}^{2}\left(o_{j}\right) \\
& \quad=\operatorname{Var}\left\{\hat{Z}\left(o_{j}\right)-Z\left(o_{j}\right)\right\} \\
& \quad=\operatorname{Var}\left\{\hat{m}\left(o_{j}\right)\right\}+\sigma_{\text {ATAK }}^{2}\left(o_{j}\right)
\end{aligned}
$$




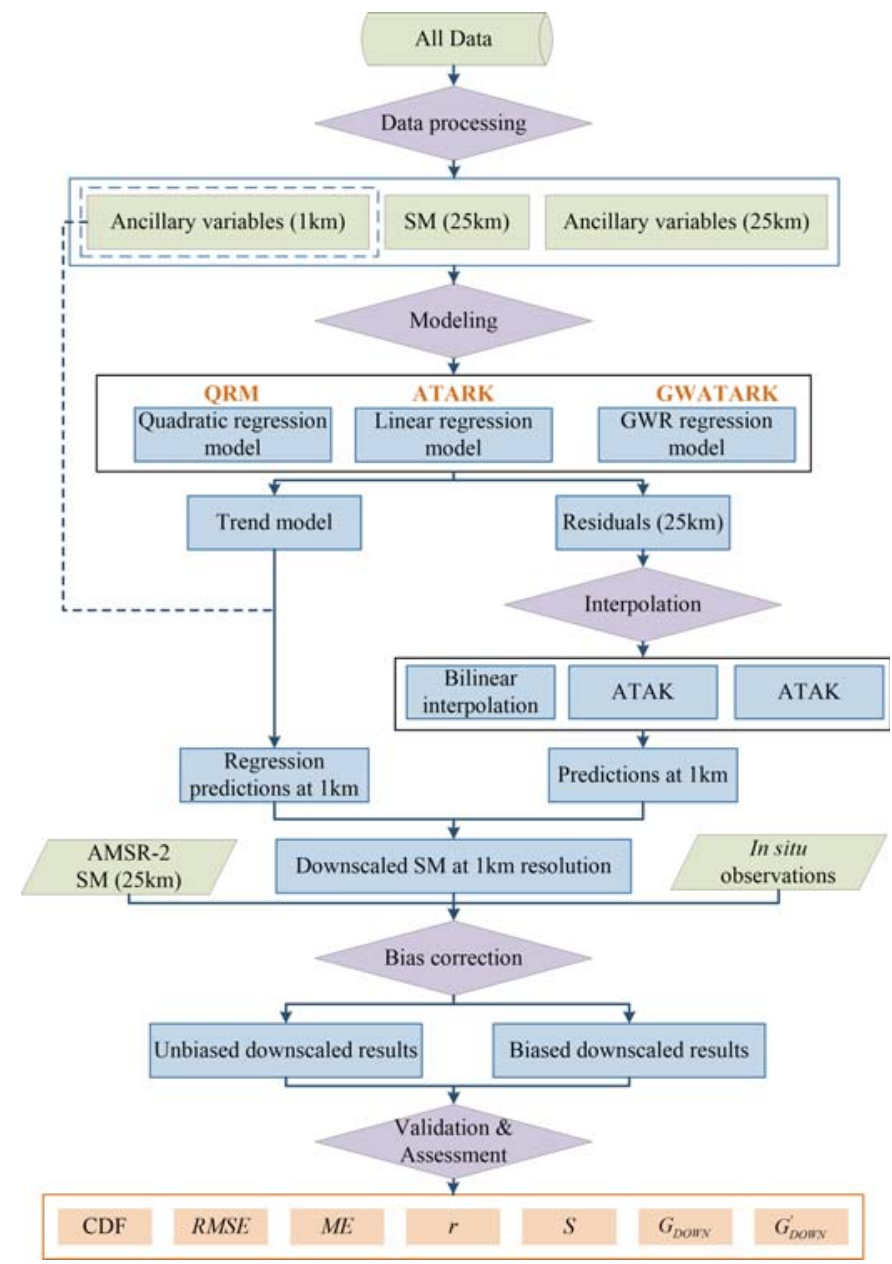

Fig. 1. Flowchart of downscaling strategy used in this paper.

$$
\begin{aligned}
= & \hat{\sigma}^{2} \boldsymbol{x}\left(o_{j}\right)^{T} \cdot\left[X^{T} W\left(O_{i}\right) X\right]^{-1} \cdot X^{T} \cdot W\left(O_{i}\right) \\
& \cdot W\left(O_{i}\right)^{T} \cdot X \cdot\left[X^{T} W\left(O_{i}\right) X\right]^{-T} \cdot \boldsymbol{x}\left(o_{j}\right) \\
& +\bar{C}\left(o_{j}, o_{j}\right)-\left[\sum_{h=1}^{m} \lambda_{h j} \bar{C}\left(O_{h}, o_{j}\right)+\mu\left(o_{j}\right)\right] .
\end{aligned}
$$

The methodology described in this section was implemented with the R software [46].

\section{EXPERIMENTS}

The proposed GWATARK method was tested on the 25-km-resolution daily AMSR-2 SM product with three sets of covariates separately, to obtain the downscaled SM at 1-km resolution. The result was compared with predictions from two similar methods, namely, ATARK and QRM. The experiments were run over both ascending and descending periods during three months (from June 2014 to September 2014) in the upstream area of the Heihe River Basin (HRB).

\section{A. Methodological Setup}

The experimental methodology included data preparation, method implementation, and validation steps (Fig. 1). First, all variables at 1 - and $25-\mathrm{km}$ spatial resolutions were preprocessed for perfect alignment within the same grid system.

Second, the three downscaling methods, which comprised spatial trend extraction and residual prediction, were applied.
The different trend models were explored at the coarse resolution of $25 \mathrm{~km}$. Based on the scale invariance of the trend, as discussed in Section II-B, the regression models of the three methods were used to predict the spatial trend of SM at the fine spatial resolution of $1 \mathrm{~km}$. Specifically, we used GWR (2) for GWATARK, ordinary linear regression for ATARK, and quadratic regression for QRM.

Third, the residuals at the fine resolution of $1 \mathrm{~km}$ were predicted from the coarse $25-\mathrm{km}$ regression residuals. Here, QRM used bilinear interpolation to downscale the coarse residuals to the fine resolution, while GWATARK and ATARK used ATAK, as explained in Section II-C. The number of coarse neighboring pixels in ATAK was taken as $m=25$. By combining the trend and residual predictions, we obtained the downscaled SM results at $1-\mathrm{km}$ resolution.

Finally, to check the proposed GWATARK method, we analyzed the downscaled results obtained by different methods across the entire study area and we compared the downscaled results with in situ observations within a subarea. Several validation measures were employed, i.e., the cumulative distribution function (CDF), root-mean-square error (RMSE) $\left(\mathrm{m}^{3} \cdot \mathrm{m}^{-3}\right)$, mean error $(\mathrm{ME})\left(\mathrm{m}^{3} \cdot \mathrm{m}^{-3}\right)$, correlation coefficient $(r)$, slope $(S)$ of the linear regression between in situ observations and remote sensing SM values, and the composite indices $G_{\mathrm{DOWN}}$ and $G_{\mathrm{DOWN}}^{\prime}$. The latter two comprise components in terms of $r, S$, and the mean bias [47]. To address any potential bias between the AMSR-2 SM values and the in situ measurements, we applied bias correction to the downscaled SM, which consist of subtracting the bias (mean difference) between the AMSR-2 SM values and the in situ measurements from the downscaled SM. Some studies have applied bias correction to remotely sensed SM products before downscaling (see [48]); however, such a procedure could cause error propagation during the downscaling process. As a preliminary exploration and given the lack of sufficient ground observations, here, we ignored error accumulation and we applied bias correction to the downscaled results before comparison with the ground reference data. After bias correction, the five indices (RMSE, ME, $r, S$, and $G_{\text {DOwN }}^{\prime}$ ) were calculated for comparison, whereby the index $G_{\text {DOWN }}^{\prime}$ should be evaluated only in terms of $r$ and $S$. The comparison results before bias correction are presented in the Appendix.

\section{B. Study Area and Materials}

1) Study Area: The study area was defined as the upper reaches of the $\mathrm{HRB}\left(37.66^{\circ}-39.16^{\circ} \mathrm{N}, 98.50^{\circ}-101.25^{\circ} \mathrm{E}\right)$ in northwestern China (Fig. 2). It includes the Babao River Basin, which is one of the focal experimental areas of the comprehensive HiWATER ecohydrological program. The study area covers approximately $2452 \mathrm{~km}^{2}$ with elevation ranging from 2640 to $5000 \mathrm{~m}$. It is a typical cold-region landscape with natural grassland as the main vegetation type. Precipitation is between 270 and $600 \mathrm{~mm}$ per year. The topography of the study area, ground-based site locations, and the AMSR-2 grid pixels are shown in Fig. 2.

2) Ground Measurements: In the upstream area of the HRB, seven ordinary automatic meteorological stations and a superstation at A'rou have been installed to capture atmospheric 


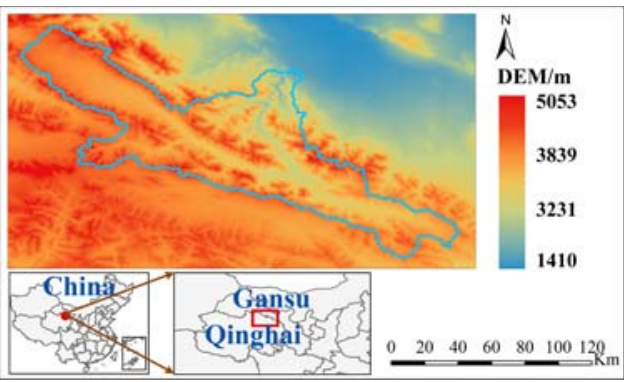

(a)

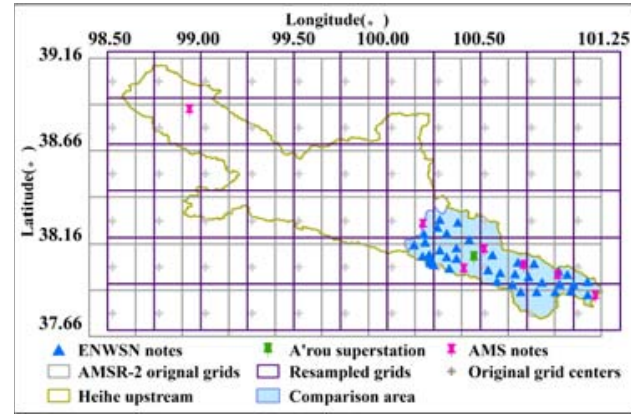

(b)

Fig. 2. (a) Elevation and delineation of the HRB study area. (b) Ground-based site locations and AMSR-2 grid pixels.

state variables (i.e., precipitation) and SM. The ecohydrological WSN (EHWSN) was designed and deployed to monitor surface SM [49]. Detailed information on instrument settings and acquired data are available in [42] and on the dedicated website of the Environmental and Ecological Science Data Center for West China (http://westdc.westgis.ac.cn/). The spatial distribution of ground stations is shown in Fig. 2(b). There are 40 EHWSN nodes obtaining data dynamically at depths of 4,10 , and $20 \mathrm{~cm}$. In this paper, three months' in situ SM observations were acquired from June 11, 2014 to September 11, 2014. For validation of the downscaled AMSR-2 SM, observations averaged over the depths of 0-4 cm during the three hours before and the three hours after the satellite overpasses were used (i.e., from 22:30 to 04:30 for the descending overpass, and from 10:30 to 16:30 for the ascending overpass). The nodes were mainly concentrated in the Babao River Basin and this part of the study area was employed as the comparison area [Fig. 2(b)] to evaluate the downscaled predictions against in situ observations. Because of the availability of remote sensing images, different periods were adopted for the validation of the descending and ascending cases. Fig. 3 shows the daily mean and standard deviation values of SM, daily cumulative rainfall for the entire study area during the two validation periods, and daily coverage fraction of MODIS. Note that as expected, the SM values are larger on rainy days.

3) Satellite Sensor Measurements: This paper employed the AMSR-2 SM, MODIS LST, MODIS NDVI, and digital elevation model (DEM) products in which the DEM is provided by the Shuttle Radar Topographic Mission (SRTM). To maintain consistency between the AMSR-2 and MODIS data, intervals of 27 and $29 \mathrm{~d}$ within the period of interest, as indicated in Fig. 3, were selected for the ascending and descending cases, respectively.

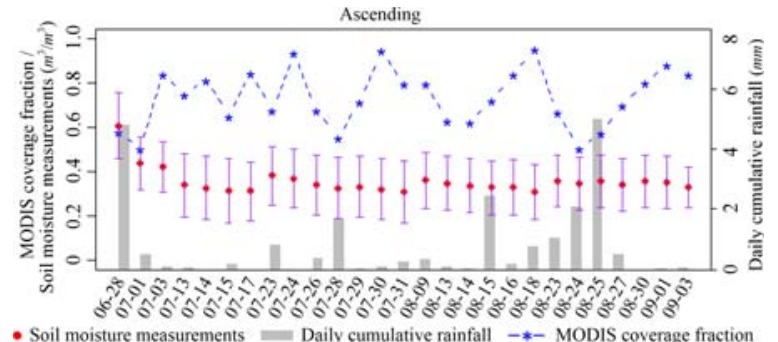

(a)

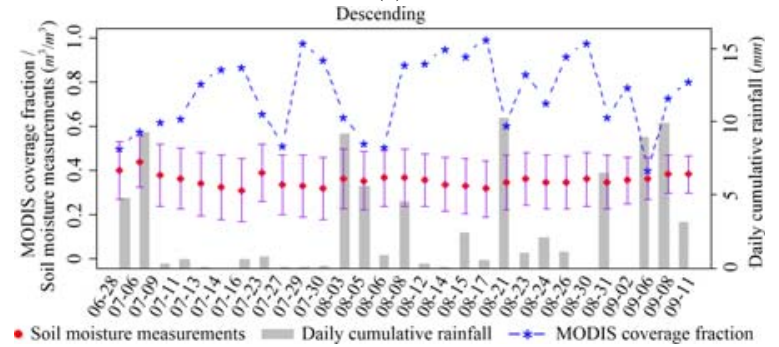

(b)

Fig. 3. SM observations, daily cumulative rainfall, and daily coverage fraction of MODIS for the entire study area during the two validation periods. (a) Ascending. (b) Descending. (The red dot is the mean and the bar is \pm 1 standard deviation.)

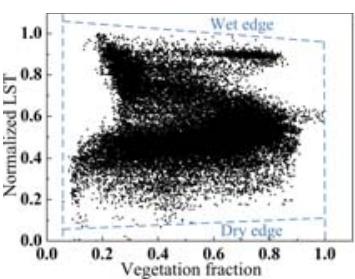

(a)

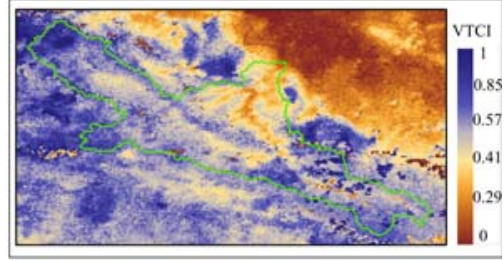

(b)
Fig. 4. (a) Vegetation-temperature trapezoidal feature space and (b) calculated VTCI at $1-\mathrm{km}$ resolution for August 21.

The successor AMSR-2 radiometer was launched on May 17, 2012, as the first satellite of the Global Change Observation Mission-Water [50], providing an important data source for global observations of SM, after the AMSR-E [51] mission was terminated in 2011. This paper used the Level 3 surface SM product of AMSR-2 (version 001), including descending and ascending data, retrieved from the X-band by the land parameter retrieval model. This data set, published by the Goddard Earth Sciences Data and Information Services Center, covers the period from May 2012 to the present at 25-km spatial resolution and 1-d temporal resolution. To match the MODIS grid data, the three months' SM data of the study area were resampled to $25 \times 25 \mathrm{~km}$ regular grids [Fig. 2(b)], using the nearest neighbor resampling technique. Only days with full spatial coverage were selected.

Given the satellite is Sun-synchronous with equator crossings at 01:30 and 13:30 local solar time, the Version 5 MODIS product of Aqua at 1-km spatial resolution was applied. The day and night LSTs were extracted from the MYD11A1 product. The NDVI data were acquired from the 16-d composite product of MYD13A2. Because of cloud disturbance, the daily MODIS product does not provide full coverage, but the 16-d NDVI product is cloud free. The daily MODIS LST product was not completely cloud free for the study area and the period considered. Only days with a high LST data coverage fraction (or no cloud fraction) were selected from all available dates. 


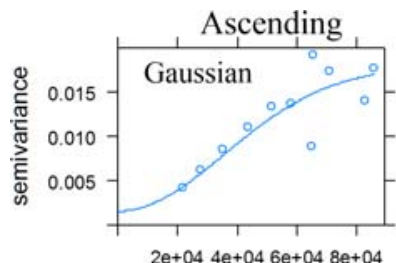

distance

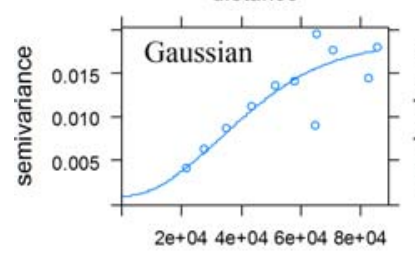

distance

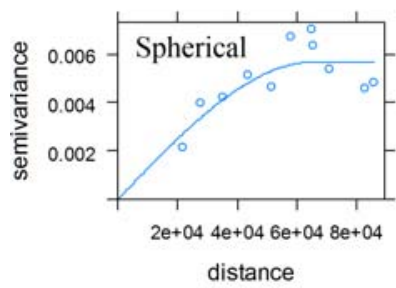

(a)

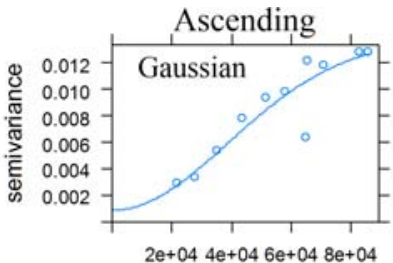

distance

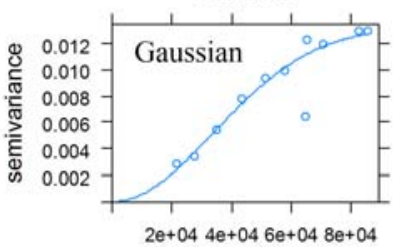

distance

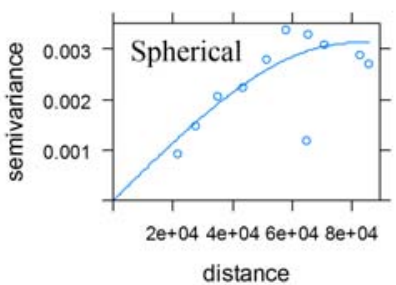

(b)

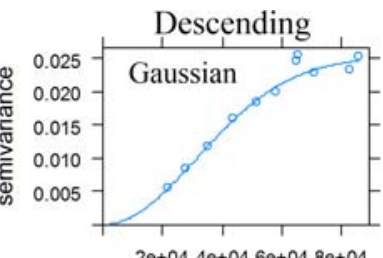

distance

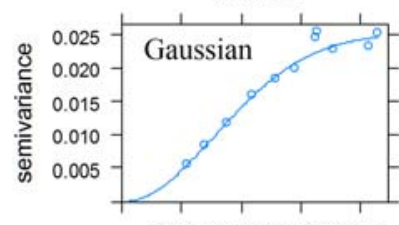

$2 e+044 e+046 e+048 e+04$

distance

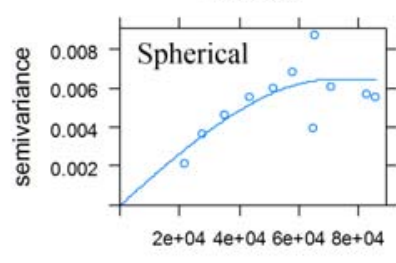

distance

(c)

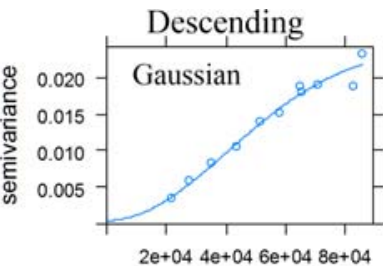

distance

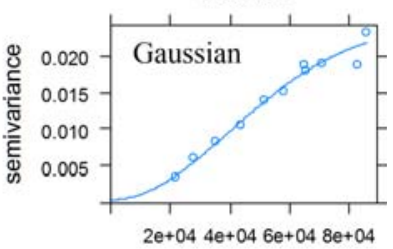

distance

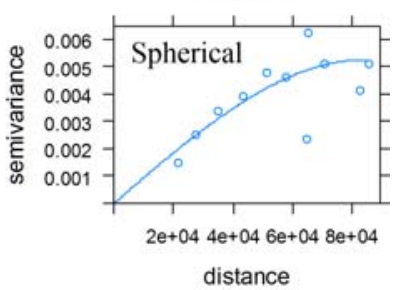

(d)

Fig. 5. Residual variograms at coarse spatial resolution (points) and fit model (lines) for the first two days in ascending and descending periods. (a) June 28. (b) July 1. (c) June 28. (d) July 6. (Each row represents one set of covariates.)

The coverage fraction values were $>0.5$. Spline interpolation was used to interpolate the pixel values in cloud-covered regions. All of the MODIS data were projected and extracted consistently with the coarse AMSR-2 data, and the aggregated coarse MODIS images achieved full coverage.

The version 4 SRTM DEM product at 90-m spatial resolution was used (http://srtm.csi.cgiar.org/index.asp). The data were resampled to $1 \times 1$ and $25 \times 25 \mathrm{~km}$ regular grids.

4) Covariates: Three sets of covariates were used in the experiments. The LST and NDVI were employed first. For August 21, the correlation coefficients between the coarseresolution SM and both LST and NDVI were -0.52 and 0.61 , respectively. The variance inflation factors of LST and NDVI were both smaller than 10 , which showed the suitability of employing these two covariates without considering multicollinearity.

Second, considering the topographic effects in the hilly surrounding area, a topography-corrected LST [21] variable was used to replace the LST of the first set. It was calculated as follows:

$$
\mathrm{CLST}=\mathrm{LST}+\gamma \cdot(H-\bar{H})
$$

where CLST is the topography-corrected LST, $H$ is the elevation of the MODIS grid, $\bar{H}$ is the elevation of the corresponding AMSR-2 grid, and $\gamma$ is the mean lapse rate $\left({ }^{\circ} \mathrm{C} \cdot \mathrm{m}^{-1}\right)$. The lapse rate was set at $0.006{ }^{\circ} \mathrm{C} \cdot \mathrm{m}^{-1}$.

The sensitivity of LST to SM varies with vegetation type, resulting in a physically meaningful triangular or trapezoidal feature space of the plotted LST and NDVI. Temperaturevegetation indices based on LST and NDVI have been used widely in estimating SM, e.g., the vegetation-temperature condition index (VTCI) [52] and the temperature-vegetation (a)
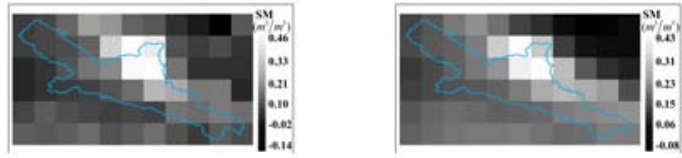

(b)
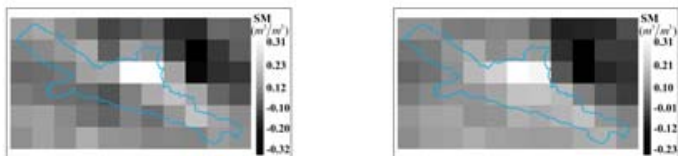

(c)

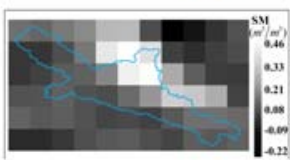

(d)
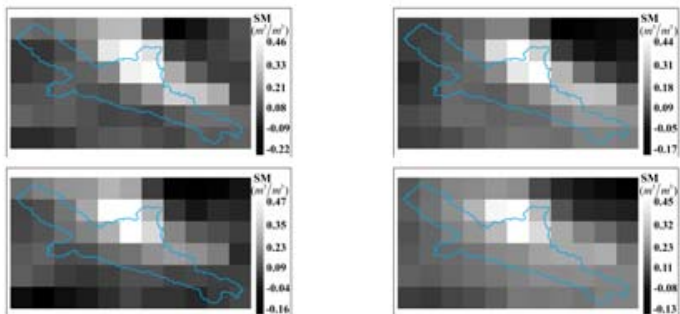

Fig. 6. Coarse residuals from regression models in ATARK and GWATARK on the first two days in ascending and descending periods. (a) June 28. (b) July 1. (c) June 28. (d) July 6. (Left) ATARK. (Right) GWATARK.

dryness index (TVDI) [53]. The VTCI is correlated positively with SM, whereas the TVDI has negative correlation with SM [54]. Here, we chose the VTCI as an independent variable of the third set. The VTCI is calculated in every NDVI interval as

$$
\mathrm{VTCI}=\frac{\mathrm{LST}_{\max }-\mathrm{LST}}{\mathrm{LST}_{\max }-\mathrm{LST}_{\min }}
$$

where $\mathrm{LST}_{\min }$ and $\mathrm{LST}_{\max }$ are the largest and smallest values of LST that lie within the same NDVI interval range. The normalized LST and the vegetation fraction cover (normalized NDVI) were employed to describe the feature space. Fig. 4 displays the vegetation-temperature feature space and 


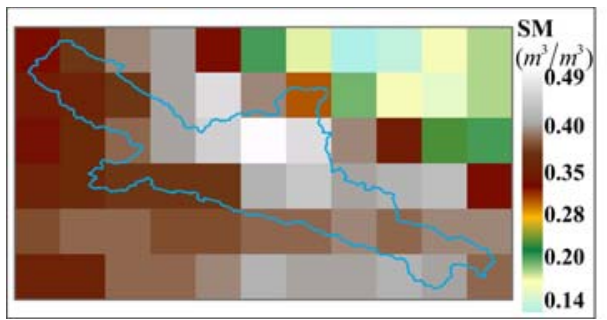

(a)

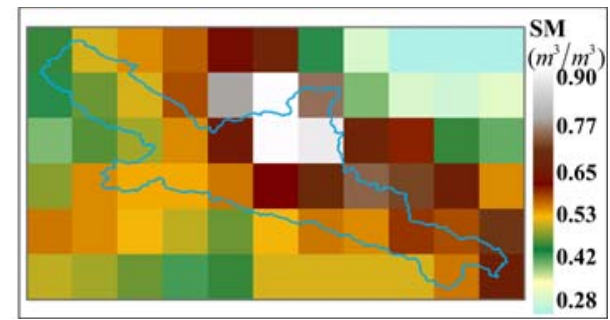

(b)

Fig. 7. Images of 25-km AMSR-2 data. (a) July 23 (ascending period). (b) August 21 (descending period).

(a)

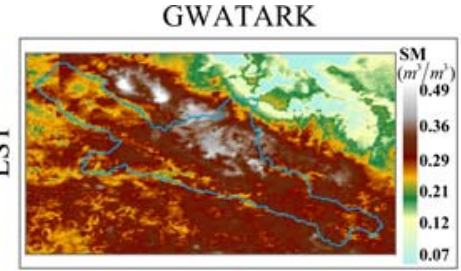

(b)

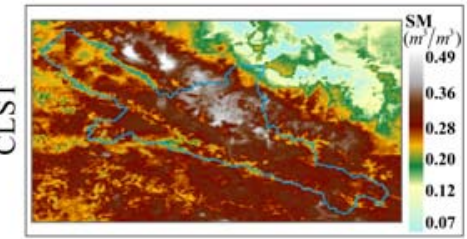

(c)

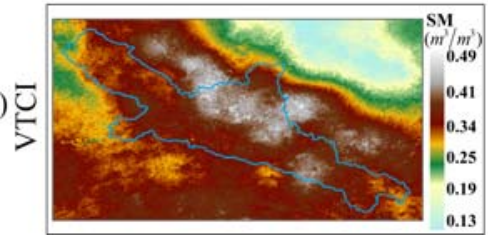

ATARK
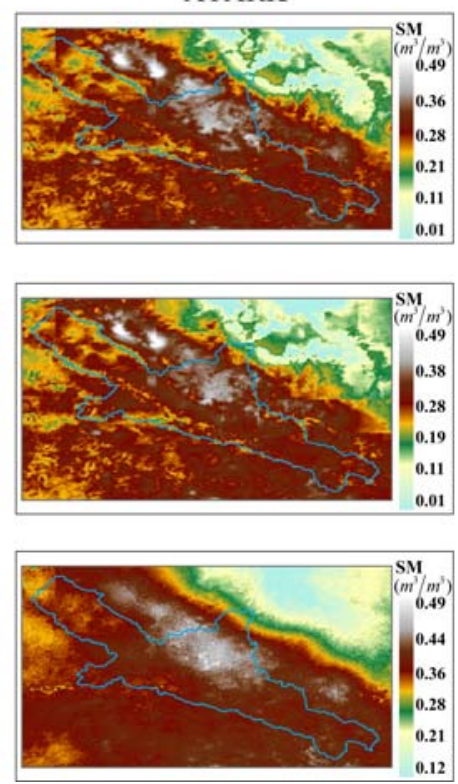
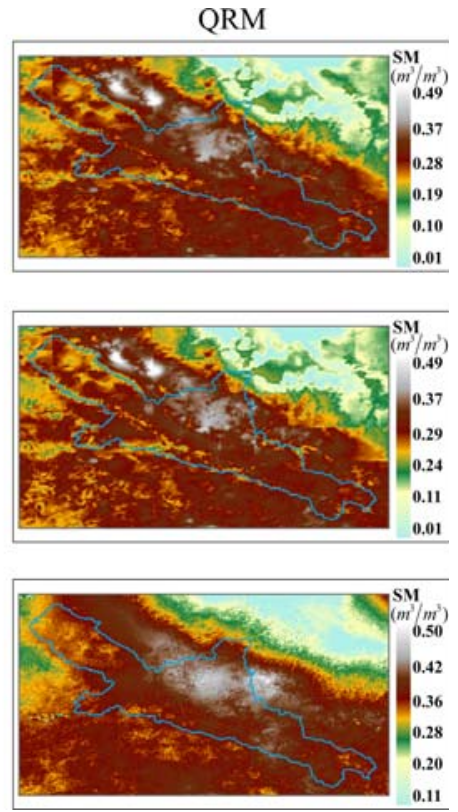

Fig. 8. Downscaled SM images on July 23 (ascending period) using three downscaling methods. (a) One-kilometer downscaled SM with $V_{\text {LST+NDVI }}$.

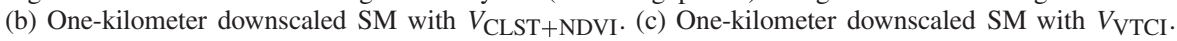

the calculated VTCI at 1-km resolution on August 21. The shape of the plotted normalized LST and vegetation fraction resembles a trapezoidal feature space; the fit line of all maximum LST values that lie within the same NDVI interval range forms the wet edge, and all minimum values form the dry edge.

In the subsequent analysis, we use $V_{\mathrm{LST}+\mathrm{NDVI}}, V_{\mathrm{CLST}+\mathrm{NDVI}}$, and $V_{\mathrm{VTCI}}$ to denote the three sets of covariates.

\section{Downscaled Results}

1) Spatial Correlation in Residuals: In the proposed method, ATAK is used to downscale the regression residuals of GWR, which depends on their spatial correlation. After automatic bandwidth selection for locally compensated ridge GWR [43], the bandwidths used in GWR ranged from 25 to $155 \mathrm{~km}$ in the ascending case and from 25 to $149 \mathrm{~km}$ in the descending case. To illustrate the spatial correlation of the residual component, variograms of the GWR residuals at coarse resolution of the first two days in the ascending and descending periods are displayed in Fig. 5. Each row corresponds to a different set of covariates, as explained in Section III-B. The clear spatial correlation indicates the feasibility of modeling the residuals with ATAK. Taking the example of $V_{\mathrm{LST}+\mathrm{NDVI}}$, the corresponding coarse residual images from the regression models in ATARK and GWATARK are shown for a few example dates in Fig. 6. The latter residuals are smoother than the former, which illustrates that GWR is better at capturing the local heterogeneity.

2) Downscaled SM Maps: To display the downscaled images, single example days for both the ascending and the descending periods were chosen. Fig. 7 shows the SM images of AMSR-2 at 25-km resolution for the chosen dates. The downscaled 1-km SM predictions on July 23 of the ascending period and on August 21 of the descending period are shown in Figs. 8 and 9, respectively. For each row of Figs. 8 and 9, the same set of covariates was used, while each column refers to one of the three downscaling approaches.

On both days, the nine downscaled images have similar overall spatial patterns (Figs. 8 and 9). The white areas in the images refer to the largest SM values. The top right corner in each image displays the smallest SM values. The GWATARK and ATARK methods produced predictions that are most similar to the coarse SM image. Some white areas (or white pixels) in the coarse SM image of the ascending case disappear in the downscaled images produced by ATARK and QRM (Fig. 8). The downscaled GWATARK images have 
(a) $\stackrel{5}{s}$
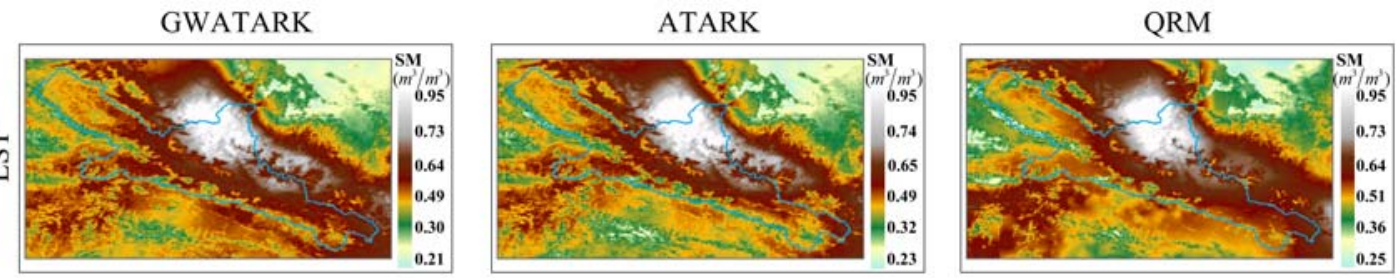

(b)
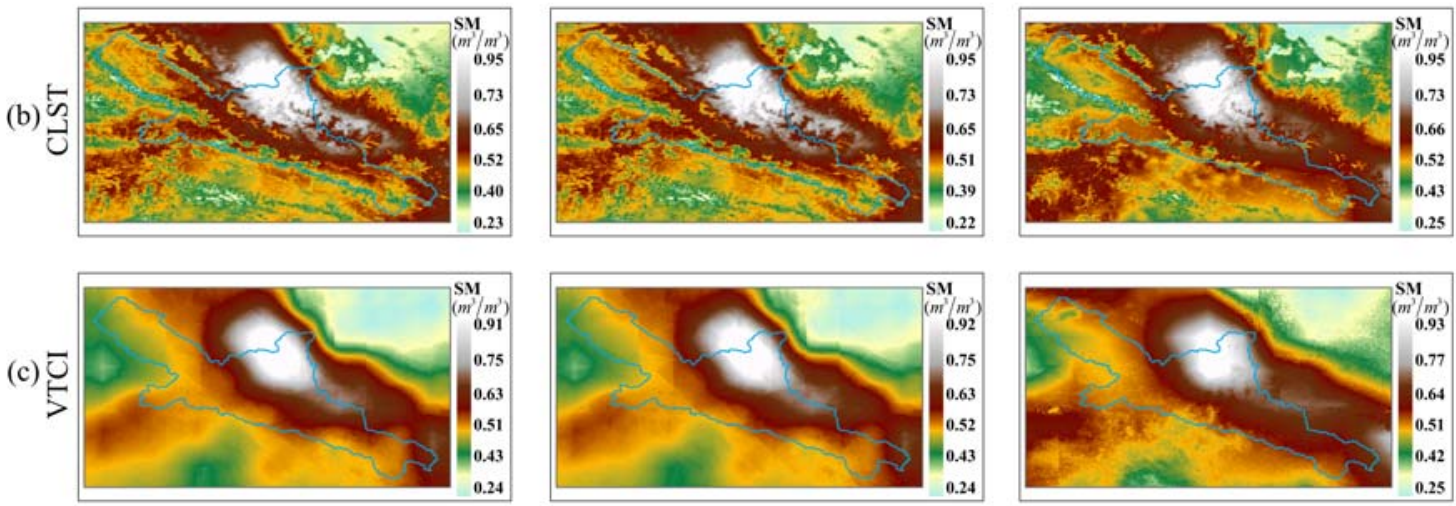

Fig. 9. Downscaled SM images on August 21 (descending period) using three downscaling methods. (a) One-kilometer downscaled SM with $V_{\text {LST+NDVI }}$ (b) One-kilometer downscaled SM with $V_{\mathrm{CLST}+\mathrm{NDVI}}$. (c) One-kilometer downscaled SM with $V_{\mathrm{VTCI}}$.

(a)

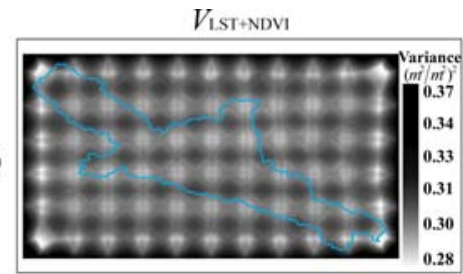

(b)

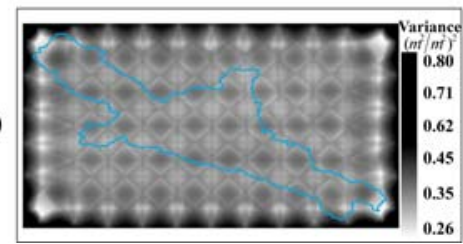

$V_{\text {CLST+NDVI }}$
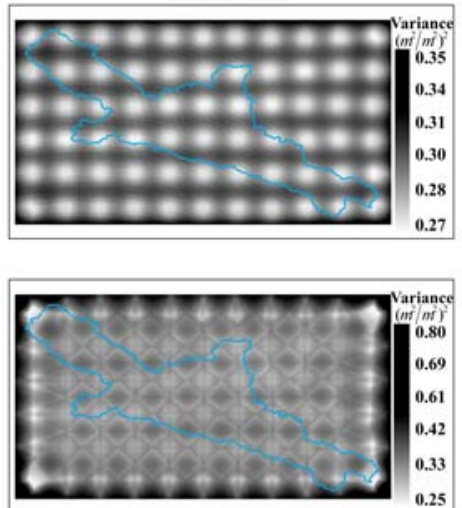
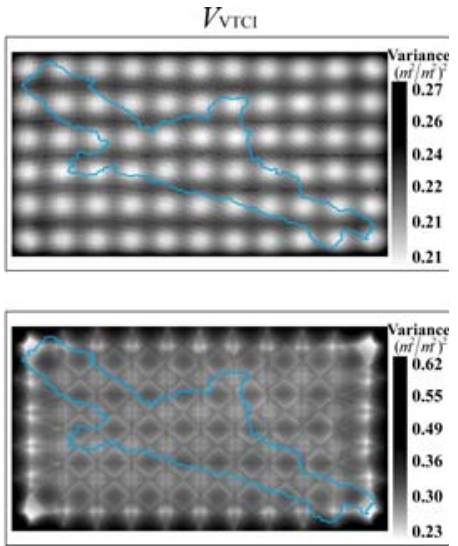

Fig. 10. Prediction error variance images of GWATARK. (a) July 23 (ascending period). (b) August 21 (descending period).

greater spatial variation than the downscaled ATARK images. Although these improvements in the descending case (Fig. 9) are not visually obvious, the following validation illustrates the good performance of GWATARK. Values greater than approximately $0.7 \mathrm{~m}^{3} \cdot \mathrm{m}^{-3}$ in the downscaled SM predictions in Fig. 9 might not agree with what could be expected in this cold region. The discrepancy might be caused by the large original SM values of the AMSR-2 data. In this paper, we focused on evaluating the downscaling methods and we did not attempt to correct further for the AMSR-2 SM product. Section III-D analyzes this more closely.

The corresponding prediction error variance images for GWATARK are shown in Fig. 10. Each column corresponds to one of the three sets of covariates. The prediction error variance increases at the edges of the coarse grids, and it reaches its maximum at the boundary of the study area. The GWR predictions in the boundary regions tend to be worse than those in other areas because of the lack of data in their neighborhoods. In $V_{\mathrm{CLST}+\mathrm{NDVI}}$ and $V_{\mathrm{VTCI}}$ cases, the prediction error variances are smaller than $V_{\mathrm{LST}+\mathrm{NDVI}}$, indicating greater prediction precision. The $V_{\mathrm{VTCI}}$ covariate produced the greatest prediction accuracy.

\section{Validation and Comparison}

CDF curves and the RMSE, ME, $r, S, G_{\mathrm{DOWN}}$, and $G_{\mathrm{DOWN}}^{\prime}$ statistics were calculated to validate and compare the downscaled results. Fig. 11 shows the CDF curves of AMSR-2 data in the study area for the $27 \mathrm{~d}$ of the ascending period and the $29 \mathrm{~d}$ of the descending period. Fig. 12 shows the CDF curves of the downscaled images for the different approaches for each of the three sets of covariates. The CDF curves of the downscaled results display trends similar to those of AMSR-2 for both periods. The percent occurrences of each SM value are similar. The CDF comparison shows that the downscaled 


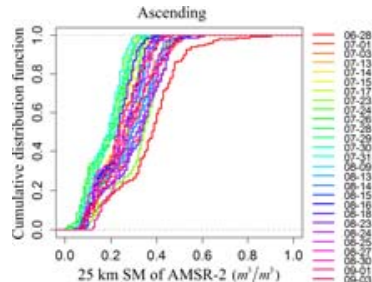

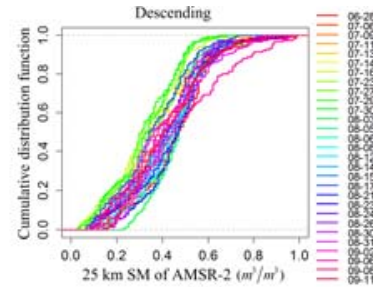

Fig. 11. CDF of 25-km SM in study area. (a) Ascending period. (b) Descending period.
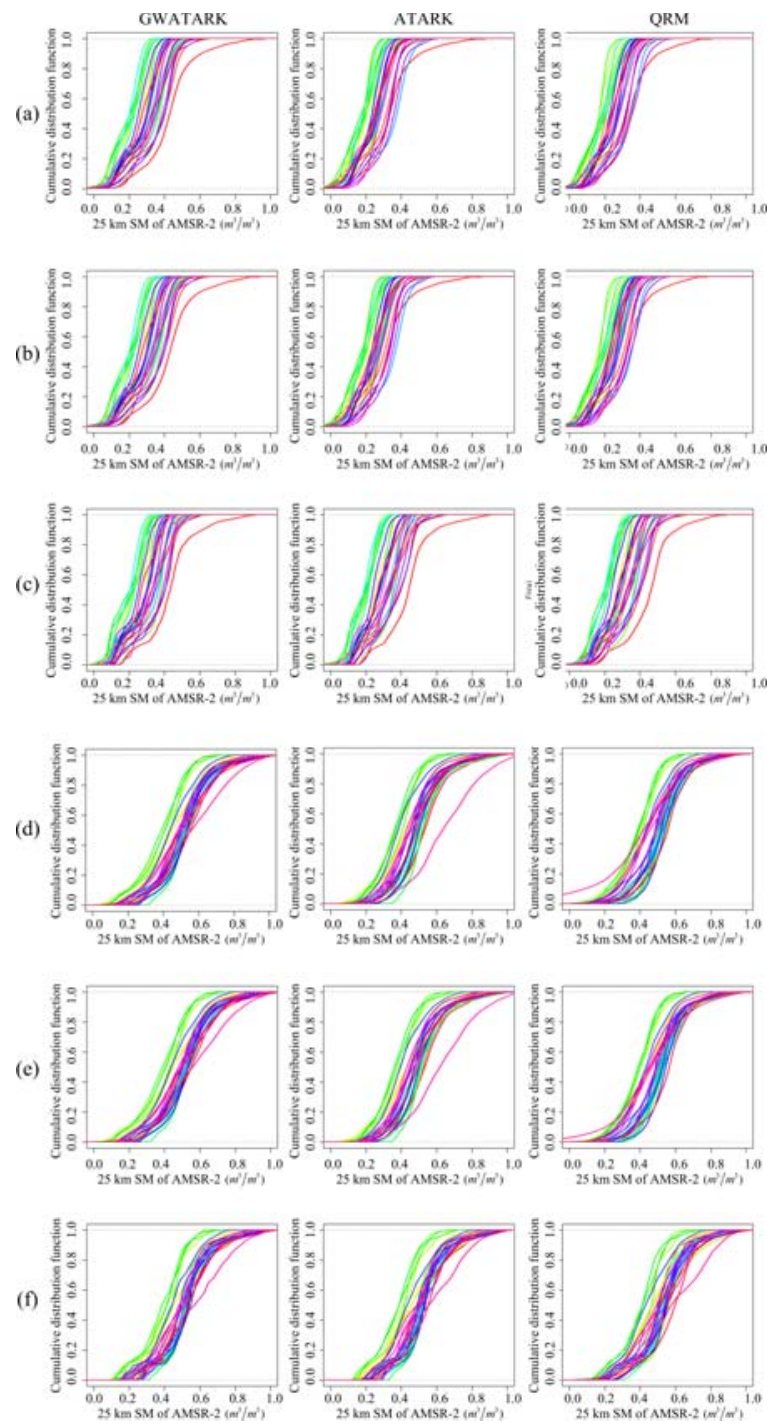

Fig. 12. $\mathrm{CDF}$ of downscaled SM including (a)-(c) ascending and (d)-(f) descending periods with $V_{\mathrm{LST}+\mathrm{NDVI}}, V_{\mathrm{CLST}+\mathrm{NDVI}}$, and $V_{\mathrm{VTCI}}$. (Legend is the same as in Fig. 11.)

results of QRM deviate substantially from those of AMSR-2, whereas the GWATARK and ATARK curves are closer.

The results of each combination of downscaling method and set of covariates were validated with in situ observations. Fig. 13 presents scatterplots comparing AMSR-2 predictions versus in situ measurements, and it summarizes the comparison results for the two periods separately. There is substantial discrepancy between the remote sensing data and the ground
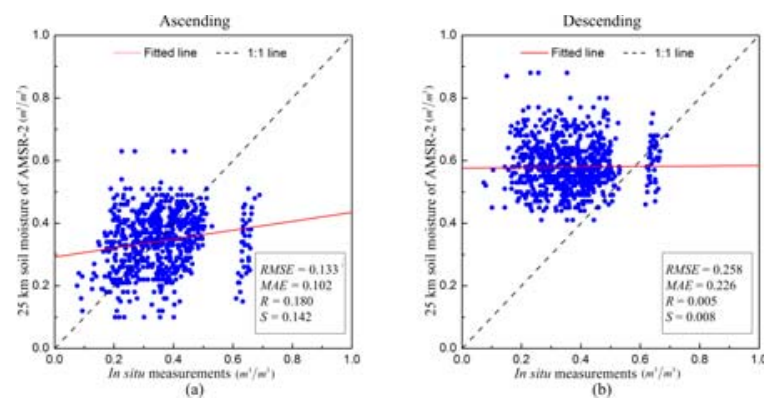

Fig. 13. Twenty-five-kilometer SM of AMSR-2 versus in situ measurements and a summary of the comparison results in the study area. (a) Ascending period. (b) Descending period.

measurements, which might be attributable to the large original SM values of the AMSR-2 data. The same situation in each method guaranteed the effectiveness of the validation results. The discrepancy is smaller in the ascending period than that in the descending period. In the descending case, the corresponding AMSR-2 SM values are almost all greater than the in situ measurements. In both cases, the values of $r$ and $S$ are small. The small correlation with the ground measurements might be caused by the difference in the spatial support between the in situ measurements and the predictions.

To provide a more suitable comparison with the ground observations, bias correction was applied to the downscaled SM, as described in Section III-A. The corrected downscaled SM predictions are plotted against the in situ measurements for the ascending and descending periods in Fig. 14, together with the results of the comparisons between different downscaling approaches.

The comparison results were consistent across the separate periods. The comparison results included RMSE, ME, $r, S$, and $G_{\text {DOWN }}^{\prime}$, which can avoid considering the mean bias again. The points were clustered around the 1:1 line and all comparison results improved substantially for both periods, especially for the ascending period. The values of RMSE and ME decreased significantly, while the values of $r$ and $S$ increased considerably. It is clear that with the smallest RMSE value of $0.018 \mathrm{~m}^{3} \cdot \mathrm{m}^{-3}$, smallest ME absolute value of $-0.002 \mathrm{~m}^{3} \cdot \mathrm{m}^{-3}$, and largest $G_{\mathrm{DOWN}}^{\prime}$ value of 1.008 , the GWATARK method using VTCI produced the greatest accuracy for the ascending period. The same conclusion holds for the descending period, with the smallest RMSE value of $0.091 \mathrm{~m}^{3} \cdot \mathrm{m}^{-3}$, smallest ME absolute value of $-0.003 \mathrm{~m}^{3} \cdot \mathrm{m}^{-3}$, and the largest $G_{\mathrm{DOWN}}^{\prime}$ value of 0.826 . The GWATARK method using CLST and NDVI obtained the second-best performance. On average, the RMSE value decreased by $20 \%$ using the proposed method. Table I shows the same statistics as Fig. 14 but for the combined ascending and descending periods. It shows that the GWATARK method using the third and second sets of covariates achieved the most accurate results for the combined period. Moreover, the comparison results before bias correction (further details in the Appendix) were consistent with the above conclusion, whereby the $G_{\text {DOwN }}$ index showed reasonable performance. The most accurate downscaled results were achieved by 

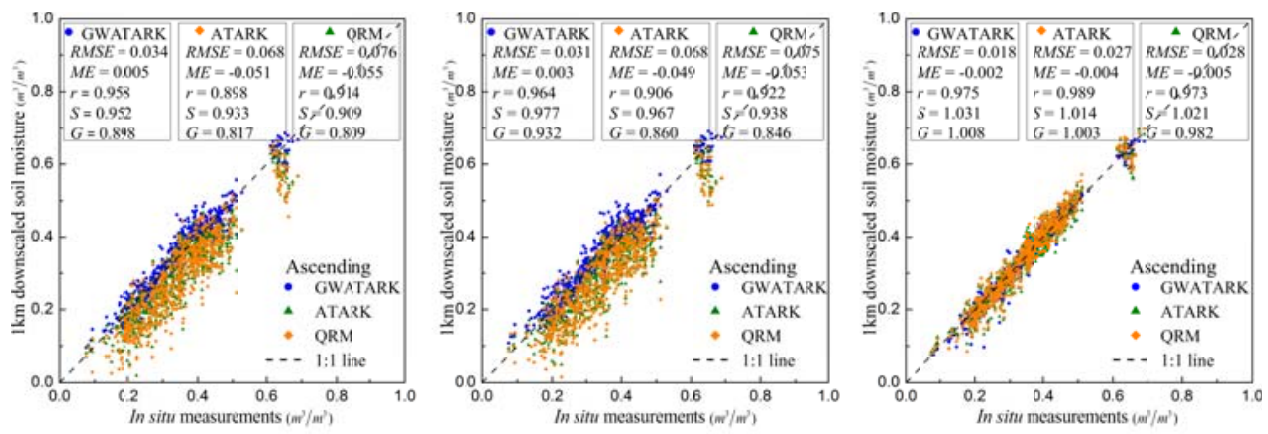

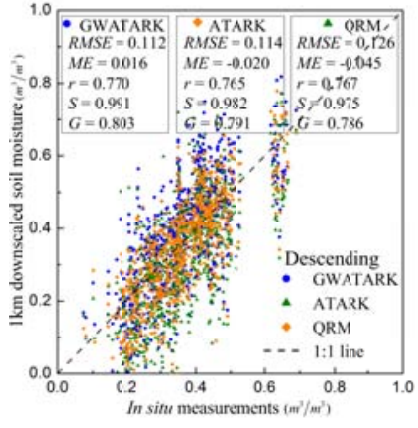

(a)

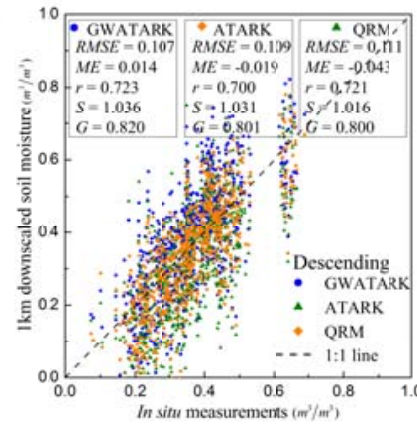

(b)

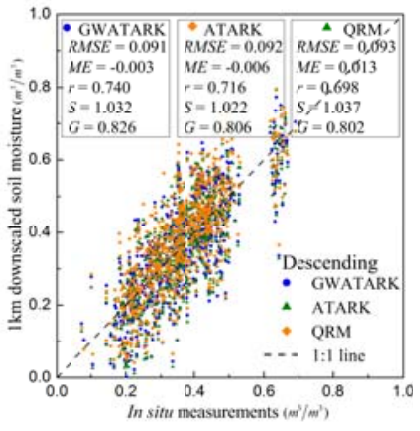

(c)

Fig. 14. Downscaled SM predictions versus in situ measurements for the ascending period and descending period. (a) With $V_{\mathrm{LST}+\mathrm{NDVI}}$. (b) With $V_{\mathrm{CLST}+\mathrm{NDVI}}$. (c) With $V_{\mathrm{VTCI}}$. $\left(G\right.$ denotes the $G_{\text {DOWN }}^{\prime}$ ) (Top row) Ascending period. (Bottom row) Descending period.

GWATARK in each set, and the accuracy of the downscaled predictions was increased by employing the final two sets of variables in each method.

\section{Discussion}

As illustrated in the experiments, all downscaled SM images exhibited the largest SM values in the upper-middle parts of the images and the smallest values in the northeast, in accordance with the low elevation of the upstream area, and the conditions of high temperature and low vegetation coverage, respectively. Because of rainfall, the SM values on August 21 were larger than those on July 23. On the descending day, the variance range was wide and the variance values were large, which might be because of the unexpectedly large values of the descending AMSR-2 SM data, introducing greater errors. The comparison of results with ground measurements also showed that the ascending product had higher data quality than the descending product. The ground stations are located within a small region of the study area. Validation could be improved by collecting data from the entire area. Because of the lack of a spatially distributed reference data set, there is a residual need to validate the spatial patterns of the downscaled SM. Some studies have retrieved SM products at coarse spatial resolution with acceptable quality using land data assimilation methods [55], [56]. Precipitation data have also been used to explore the spatial pattern of SM [57]. In future research, cross validation and further exploration of the spatial SM patterns could be achieved by comparison with the downscaled results of SM assimilation data sets and fineresolution precipitation data sets.
The GWATARK method produces predictions that are more accurate when the property of interest is spatially heterogeneous. It should be noted that the differences between the predictions and the observations are caused not only by prediction errors, but also by measurement errors and the comparison of variables at different resolutions [58], [59], i.e., point values versus either $1 \times 1 \mathrm{~km}$ regular grid predictions or $25 \times 25 \mathrm{~km}$ regular grid predictions. To some extent, the downscaling indices $G_{\text {DOWN }}$ and $G_{\text {DOWN }}^{\prime}$ could overcome these shortcomings. After removing the bias between the AMSR-2 SM values and the in situ measurements, the values of the five accuracy statistics (Table I) were improved significantly. The results demonstrate the applicability of GWATARK in a downscaling process. Geostatistical upscaling approaches (such as block kriging) could be used to upscale point observations to a $1 \times 1 \mathrm{~km}$ grid before validation. However, upscaling also introduces uncertainties that should be considered when making comparisons between predictions and upscaled observations. In future research, ground measurement errors could be considered in a downscaling strategy to increase prediction accuracy, e.g., as a priori knowledge or correction data during the downscaling process.

In this paper, only one or two ancillary variables were used as covariates in the downscaling process. Based on the accuracy statistics, it could be concluded that the downscaling method using the VTCI performed more accurately than the others for each period. However, the downscaled images using VTCI (Figs. 8 and 9) display much smoother variation. Although some covariates combine LST and NDVI information, some information will be lost when using just one covariate. In fact, multiple variables can be employed 
TABLE I

Summary Statistics of Comparison Between Downscaled Predictions and In Situ Measurements Combining Two Periods. CR Refers To the Corresponding AMSR-2 Data at CoARse Resolution. FR ReFERs to the Downscaled Predictions at Fine Resolution

\begin{tabular}{|c|c|c|c|c|c|c|c|c|c|c|}
\hline & \multirow{2}{*}{ CR } & \multicolumn{2}{|c|}{ GWATARK } & \multirow[b]{2}{*}{$\mathrm{FR}_{V \mathrm{VTCI}}$} & \multicolumn{2}{|c|}{ ATARK } & \multicolumn{3}{|c|}{ QRM } & \multirow[b]{2}{*}{$\mathrm{FR}_{V \mathrm{VTC}}$} \\
\hline & & $\overline{F R_{\ell L S T+N D V I}}$ & $\overline{\mathrm{FR}}_{V \mathrm{CLST}+\mathrm{NDVI}}$ & & $\overline{\mathrm{FR}_{\text {LST }+\mathrm{NDVI}}}$ & $\mathrm{FR}_{V \mathrm{CLST}+\mathrm{NDVI}}$ & $\mathrm{FR}_{V \mathrm{VTCI}}$ & $\overline{\mathrm{FR}_{h L S \mathrm{~T}+\mathrm{NDVI}}}$ & $\mathrm{FR}_{V \mathrm{CLST}+\mathrm{NDVI}}$ & \\
\hline$R M S E$ & 0.208 & 0.085 & 0.080 & 0.067 & 0.095 & 0.092 & 0.069 & 0.105 & 0.096 & 0.070 \\
\hline$M E$ & 0.111 & 0.011 & 0.009 & -0.003 & -0.035 & -0.033 & -0.005 & -0.050 & -0.048 & 0.004 \\
\hline$r$ & 0.091 & 0.814 & 0.809 & 0.891 & 0.787 & 0.793 & 0.850 & 0.786 & 0.755 & 0.824 \\
\hline$S$ & 0.118 & 0.990 & 0.996 & 1.031 & 0.965 & 0.990 & 1.017 & 0.959 & 0.987 & 1.014 \\
\hline$G_{\text {DOWN }}^{\prime}$ & - & 0.819 & 0.822 & 0.929 & 0.772 & 0.803 & 0.878 & 0.765 & 0.773 & 0.854 \\
\hline
\end{tabular}

TABLE II

Summary Statistics of Comparison Between Remote Sensing Data and In Situ Measurements From Ascending and Descending Periods Before Bias Correction. CR Refers to AMSR-2 Data at Coarse Resolution. FR Refers to the Downscaled Predictions at Fine Resolution

\begin{tabular}{|c|c|c|c|c|c|c|c|c|c|c|}
\hline & \multirow{2}{*}{$\mathrm{CR}$} & \multicolumn{2}{|c|}{ GWATARK } & \multirow[b]{2}{*}{$\mathrm{FR}_{V \mathrm{VTCI}}$} & \multicolumn{2}{|l|}{ ATPRK } & \multirow{3}{*}{$\mathrm{FR}_{V \mathrm{VTCI}}$} & \multicolumn{2}{|l|}{ QRM } & \multirow[b]{2}{*}{$\mathrm{FR}_{V \mathrm{VTCI}}$} \\
\hline & & $\mathrm{FR}_{\text {ИST+NDVI }}$ & $\mathrm{FR}_{V \mathrm{CLST}+\mathrm{NDVI}}$ & & $\mathrm{FR}_{\ell \mathrm{LST}+\mathrm{NDVI}}$ & $\mathrm{FR}_{V C L S T+N D V I}$ & & $\mathrm{FR}_{И \mathrm{LST}+\mathrm{NDVI}}$ & $\mathrm{FR}_{V C L S T+N D V I}$ & \\
\hline \multicolumn{10}{|c|}{ Ascending } & \\
\hline RMSE & 0.133 & 0.139 & 0.130 & 0.128 & 0.147 & 0.145 & 0.132 & 0.149 & 0.146 & 0.136 \\
\hline$M E$ & -0.011 & -0.013 & -0.008 & -0.005 & -0.065 & -0.058 & -0.019 & -0.068 & -0.062 & -0.021 \\
\hline$r$ & 0.180 & 0.149 & 0.116 & 0.201 & 0.116 & 0.102 & 0.191 & 0.155 & 0.107 & 0.212 \\
\hline$S$ & 0.142 & 0.120 & 0.108 & 0.156 & 0.104 & 0.098 & 0.155 & 0.101 & 0.075 & 0.173 \\
\hline$G_{\text {DOWN }}$ & - & -0.038 & 0.034 & 0.132 & -0.257 & -0.253 & -0.084 & -0.253 & -0.260 & -0.091 \\
\hline \multicolumn{11}{|c|}{ Descending } \\
\hline$R M S E$ & 0.258 & 0.270 & 0.234 & 0.231 & 0.275 & 0.252 & 0.250 & 0.277 & 0.256 & 0.253 \\
\hline$M E$ & 0.221 & 0.198 & 0.178 & 0.173 & 0.234 & 0.216 & 0.191 & 0.247 & 0.223 & 0.192 \\
\hline$r$ & 0.005 & 0.023 & 0.030 & -0.034 & 0.036 & 0.022 & -0.042 & 0.039 & 0.047 & -0.048 \\
\hline$S$ & 0.008 & 0.019 & 0.022 & -0.025 & 0.024 & 0.030 & -0.034 & 0.021 & 0.031 & -0.035 \\
\hline$G_{\text {DOWN }}$ & - & 0.023 & 0.043 & 0.029 & -0.002 & 0.011 & 0.009 & -0.011 & 0.010 & 0.008 \\
\hline
\end{tabular}

readily in the proposed method. The selection of further multiple covariates is encouraged to improve mapping, provided these covariates carry complementary information about SM. Candidate additional covariates are land cover maps, apparent thermal inertia [60], and soil texture information [61].

The geostatistical part of GWATARK operates on the residuals of the GWR. It was assumed that the residuals satisfy a stationarity assumption such that their spatial correlation could be characterized by a variogram that depends only on the separation distance between locations. Because GWR is a local regression approach, it is more efficient than a global regression model in removing local heterogeneity. Thus, the corresponding residuals might not vary greatly from area to area and might not meet the stationarity assumption as readily. If the GWR model captured the full spatial structure of SM, the residuals of GWR might become uncorrelated spatially (i.e., white noise) meaning that spatial prediction could not benefit from a kriging step. In such a case, GWATARK would reduce to GWR.

If the target spatial resolution was very fine, such that the pixels at the fine resolution might be regarded as points, an alternative method named geographically weighted areato-point regression kriging (GWATPRK) could be used. This method uses ATPK instead of ATAK. Then, the main challenge is that the point support nugget cannot easily be inferred from the block support observations [62]. Moreover, the GWATARK method is more general. For example, when dealing with variables with irregular support (e.g., administrative units), the proposed GWATARK method will be more applicable than GWATPRK. However, it should be noted that downscaling methods could only be applied on cloud-free days because of the requirements of optical/thermal data.

The methodology presented here was restricted to continuous variables, but otherwise, it has few restrictions. Thus, GWATARK downscaling could be achieved readily for other continuous variables such as rainfall, temperature, and wind speed. Here, outcomes of coarse-resolution weather models could be used as input variables that are then downscaled using fine-resolution covariates.

\section{CONCLUSION}

SM observations from satellite sensors are made at coarse spatial resolution, and their subsequent downscaling using covariates represents an important objective. Downscaling is now being applied to transform coarse-spatial-resolution SM observations to fine resolution to support monitoring and modeling over large areas. This paper developed a new downscaling approach that combines GWR with ATAK that is applicable to downscaling SM. The new GWATARK method was demonstrated through application to the AMSR-2 SM product in the upper reaches of the HRB. Compared with two benchmark downscaling methods (ATARK and QRM), the GWATARK method produced downscaled SM images that were more accurate as measured by five accuracy metrics, and it emerged as the most accurate method for downscaling SM from coarse-resolution remotely sensed images. The GWATARK method has the dual advantages of addressing local spatial heterogeneity and the COSP. A further important advantage in comparison with deterministic downscaling approaches, in addition to deriving the downscaled predictions, 

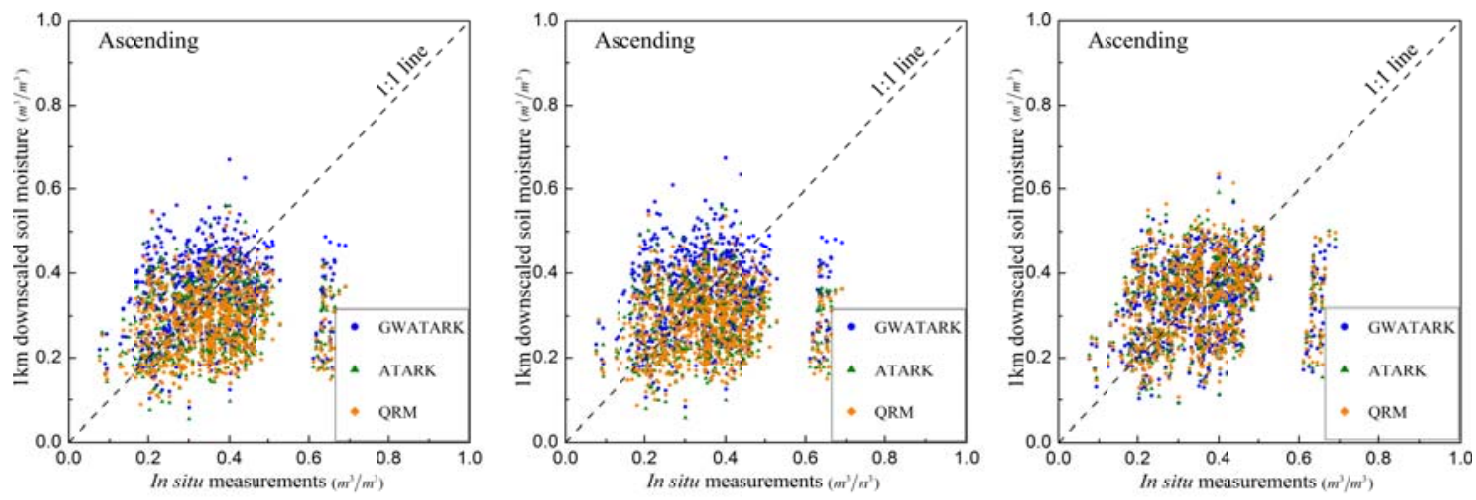

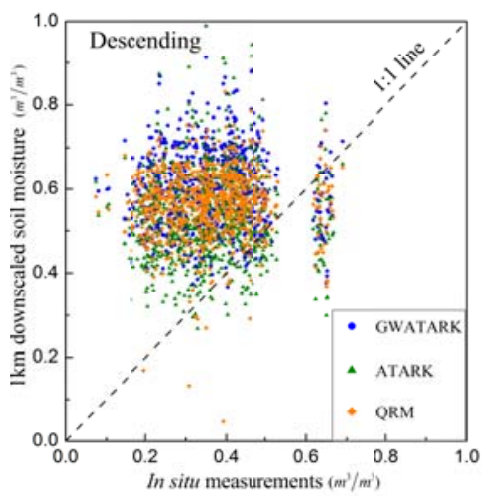

(a)

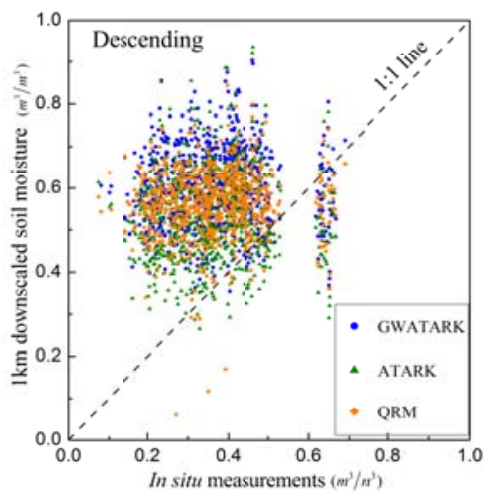

(b)

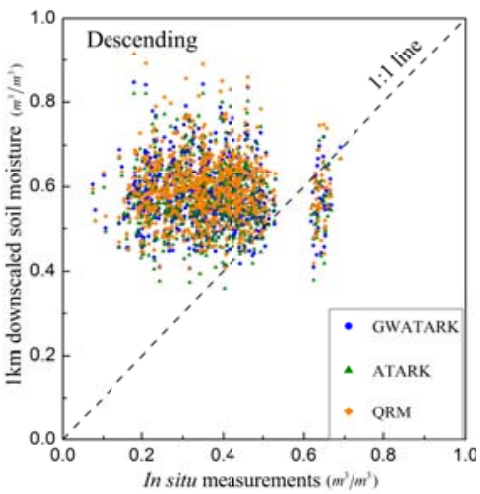

(c)

Fig. 15. Downscaled SM predictions versus in situ measurements for ascending and descending periods before bias correction. (a) $V_{\mathrm{LST}+\mathrm{NDVI}}$. (b) $V_{\mathrm{CLST}+\mathrm{NDVI}}$ (c) $V_{\mathrm{VTCI}}$.

TABLE III

Summary Statistics of Comparison Between Remote Sensing Data and In Situ Measurements Combining Two Periods BEFore Bias CORRECTION. CR REFERS to THE CORRESPONDING AMSR-2 DAtA AT COARSE RESOlUtion. FR REFERS to the Downscaled PRedictions at Fine Resolution

\begin{tabular}{|c|c|c|c|c|c|c|c|c|c|c|}
\hline & \multirow{2}{*}{$\mathrm{CR}$} & \multicolumn{2}{|c|}{ GWATARK } & \multirow[b]{2}{*}{$\mathrm{FR}_{V \mathrm{VTCl}}$} & \multicolumn{2}{|l|}{ ATPRK } & \multicolumn{3}{|c|}{ QRM } & \multirow[b]{2}{*}{$\mathrm{FR}_{V \mathrm{VTCI}}$} \\
\hline & & $\mathrm{FR}_{h \mathrm{LST}+\mathrm{NDVI}}$ & $\mathrm{FR}_{V \mathrm{CLST}+\mathrm{NDVI}}$ & & $\mathrm{FR}_{V \mathrm{LST}+\mathrm{NDVI}}$ & $\mathrm{FR}_{V \mathrm{CLST}+\mathrm{NDVI}}$ & $\mathrm{FR}_{V \mathrm{VTCI}}$ & $\mathrm{FR}_{h L S T+\mathrm{NDVI}}$ & $\mathrm{FR}_{V \mathrm{CLST}+\mathrm{NDVI}}$ & \\
\hline RMSE & 0.208 & 0.218 & 0.192 & 0.189 & 0.224 & 0.208 & 0.203 & 0.226 & 0.211 & 0.206 \\
\hline$M E$ & 0.111 & 0.098 & 0.090 & 0.089 & 0.092 & 0.086 & 0.091 & 0.098 & 0.088 & 0.091 \\
\hline$r$ & 0.091 & 0.103 & 0.092 & 0.128 & 0.077 & 0.058 & 0.102 & 0.087 & 0.051 & 0.096 \\
\hline$S$ & 0.118 & 0.117 & 0.094 & 0.127 & 0.064 & 0.054 & 0.104 & 0.071 & 0.058 & 0.131 \\
\hline$G_{\text {DOWN }}$ & - & 0.023 & 0.031 & 0.046 & 0.018 & 0.025 & 0.032 & 0.013 & 0.021 & 0.036 \\
\hline
\end{tabular}

is that the associated prediction error variances are also obtained. The applicability of three different sets of covariates in the downscaling process was also analyzed. CLST was found to be more informative than both LST and VTCI, and it led to the most accurate downscaled predictions. Moreover, the validation data were obtained with quasi-point support and they contained measurement errors. Therefore, further assessment is warranted using ground data that are more representative. The proposed method is entirely general and it could be applied to downscale other continuous variables obtained by remote sensing both in the optical and in the microwave domains.

\section{APPENDIX}

The comparison results obtained before bias correction were represented here using five indices (RMSE, ME, $r, S$, and $\left.G_{\text {DOWN }}\right)$. Fig. 15 shows the comparison scatterplots of the downscaled predictions versus in situ measurements for both periods. The clustering of points is similar to that in Fig. 13. The downscaled predictions are almost all above the 1:1 line in the descending case. Table II shows summary statistics of the comparison between remote sensing data (including the AMSR-2 data and downscaled data) and in situ measurements for the ascending and descending periods, separately. The RMSE and ME of the downscaled results are not smaller than those of the coarse-resolution case, i.e., they are around 0.133 and $-0.011 \mathrm{~m}^{3} \cdot \mathrm{m}^{-3}$ for the ascending case and 0.258 and $0.221 \mathrm{~m}^{3} \cdot \mathrm{m}^{-3}$ for the descending case, respectively. For each downscaled result in each period, the $r$ values were small and the $S$ values were not close to 1 .

For each set of covariates, the RMSE and ME of the GWATARK method were smaller than those of ATARK and QRM, while the $G_{\text {DOWN }}$ values were greater than those of the other two methods. These results demonstrate that 
the GWATARK downscaling method attained more accurate downscaled predictions than the other two methods for both periods. By comparing the results among the three sets of covariates, the RMSE and ME of the latter two sets were smaller than those of the first set and the $G_{\text {DOWN }}$ values were greater. This indicates that using $V_{\mathrm{CLST}+\mathrm{NDVI}}$ and $V_{\mathrm{VTCI}}$ increased the downscaled prediction accuracy. The RMSE, $\mathrm{ME}$, and $G_{\text {DOwn }}$ showed the method performed more accurately for the third set than for the second set, in addition to the $G_{\text {DOWN }}$ values for the descending period. This might reflect the negative values of $r$ and $S$ in every third set of the descending period, for which the corresponding values were positive at coarse resolution. Moreover, the values of $r$ and $S$ varied with little regularity. The largest value of $r$ was obtained for the third set. This set also produced values of $S$ closest to 1 . Table III shows the same statistics as Table II but for the combined ascending and descending periods. The most accurate values of RMSE, ME, and $G_{\text {DOWN }}$, i.e., $0.189 \mathrm{~m}^{3} \cdot \mathrm{m}^{-3}, 0.089 \mathrm{~m}^{3} \cdot \mathrm{m}^{-3}$, and 0.046 , respectively, were obtained using the GWATARK method. The comparison results were consistent between the periods. From Tables II and III, the produced RMSE, ME, $r$, and $S$ values indicate that the predictions still deviated greatly from the in situ observations, primarily because of the bias between the AMSR-2 SM values and the in situ measurements, although the $G_{\text {DOWN }}$ index showed reasonable performance. In general, the results indicate that the GWATARK downscaling method achieved the greatest accuracy, and that the latter two sets of independent variables increased the accuracy of the downscaled predictions.

\section{ACKNOWLEDGMENT}

The authors would like to thank all data producers.

\section{REFERENCES}

[1] J. Qin, S. Liang, K. Yang, I. Kaihotsu, R. Liu, and T. Koike, "Simultaneous estimation of both soil moisture and model parameters using particle filtering method through the assimilation of microwave signal," J. Geophys. Res., Atmos., vol. 114, no. D15, p. D15103, 2009.

[2] H. Vereecken et al., "On the spatio-temporal dynamics of soil moisture at the field scale," J. Hydrol., vol. 516, pp. 76-96, Aug. 2014.

[3] H. R. Bogena, M. Herbst, J. A. Huisman, U. Rosenbaum, A. Weuthen, and $\mathrm{H}$. Vereecken, "Potential of wireless sensor networks for measuring soil water content variability," Vadose Zone J., vol. 9, pp. 1002-1013, 2010.

[4] M. Zreda, D. Desilets, T. P. A. Ferré, and R. L. Scott, "Measuring soil moisture content non-invasively at intermediate spatial scale using cosmic-ray neutrons," Geophys. Res. Lett., vol. 35, no. 21, p. L21402, 2008.

[5] W. Wagner et al., "Operational readiness of microwave remote sensing of soil moisture for hydrologic applications," Hydrol. Res., vol. 38, no. 1, pp. 1-20, 2007.

[6] N. E. C. Verhoest et al., "Copula-based downscaling of coarse-scale soil moisture observations with implicit bias correction," IEEE Trans. Geosci. Remote Sens., vol. 53, no. 6, pp. 3507-3521, Jun. 2015.

[7] D. J. Wilson, A. W. Western, and R. B. Grayson, "A terrain and databased method for generating the spatial distribution of soil moisture," Adv. Water Resour., vol. 28, no. 1, pp. 43-54, Jan. 2005.

[8] P. K. Srivastava, D. Han, M. R. Ramirez, and T. Islam, "Machine learning techniques for downscaling SMOS satellite soil moisture using MODIS land surface temperature for hydrological application," Water Resour. Manage., vol. 27, no. 8, pp. 3127-3144, Jun. 2013.

[9] A. K. Sahoo, G. J. M. De Lannoy, R. H. Reichle, and P. R. Houser, "Assimilation and downscaling of satellite observed soil moisture over the Little River Experimental Watershed in Georgia, USA," Adv. Water Resour., vol. 52, pp. 19-33, Feb. 2013.
[10] G. Mascaro, E. R. Vivoni, and R. Deidda, "Downscaling soil moisture in the southern Great Plains through a calibrated multifractal model for land surface modeling applications," Water Resour. Res., vol. 46, no. 8, p. W08546, 2010.

[11] D. Thattai and S. Islam, "Spatial analysis of remotely sensed soil moisture data," J. Hydrol. Eng., vol. 5, no. 4, pp. 386-392, 2000.

[12] Y. H. Kaheil, E. Rosero, M. K. Gill, M. McKee, and L. A. Bastidas, "Downscaling and forecasting of evapotranspiration using a synthetic model of wavelets and support vector machines," IEEE Trans. Geosci. Remote Sens., vol. 46, no. 9, pp. 2692-2707, Sep. 2008.

[13] J. Peng, A. Loew, O. Merlin, and N. E. C. Verhoest, "A review of spatial downscaling of satellite remotely sensed soil moisture," Rev. Geophys., vol. 55, no. 2, pp. 341-366, Jun. 2017.

[14] J. Van Doninck, J. Peters, B. De Baets, E. M. De Clercq, E. Ducheyne, and N. E. C. Verhoest, "The potential of multitemporal Aqua and Terra MODIS apparent thermal inertia as a soil moisture indicator," Int. J. Appl. Earth Observ. Geoinf., vol. 13, no. 6, pp. 934-941, Dec. 2011.

[15] M. Piles et al., "Downscaling SMOS-derived soil moisture using MODIS visible/infrared data," IEEE Trans. Geosci. Remote Sens., vol. 49, no. 9, pp. 3156-3166, Sep. 2011

[16] S. Chakrabarti, J. Judge, T. Bongiovanni, A. Rangarajan, and S. Ranka, "Disaggregation of remotely sensed soil moisture in heterogeneous landscapes using holistic structure-based models," IEEE Trans. Geosci. Remote Sens., vol. 54, no. 8, pp. 4629-4641, Aug. 2016.

[17] N. S. Chauhan, S. Miller, and P. Ardanuy, "Spaceborne soil moisture estimation at high resolution: A microwave-optical/IR synergistic approach," Int. J. Remote Sens., vol. 24, no. 22, pp. 4599-4622, 2003.

[18] R. L. Ray, J. M. Jacobs, and M. H. Cosh, "Landslide susceptibility mapping using downscaled AMSR-E soil moisture: A case study from Cleveland Corral, California, US," Remote Sens. Environ., vol. 114 no. 11, pp. 2624-2636, Nov. 2010.

[19] G. Yu, L. Di, and W. Yang, "Downscaling of global soil moisture using auxiliary data," in Proc. IEEE Geosci. Remote Sens. Symp. (IGARSS), vol. 3. Jul. 2008, pp. 230-233.

[20] Y. Malbéteau, O. Merlin, B. Molero, C. Rüdiger, and S. Bacon, "DisPATCh as a tool to evaluate coarse-scale remotely sensed soil moisture using localized in situ measurements: Application to SMOS and AMSR-E data in Southeastern Australia," Int. J. Appl. Earth Observ. Geoinf., vol. 45, pp. 221-234, Mar. 2016.

[21] O. Merlin, M. J. Escorihuela, M. A. Mayoral, O. Hagolle, A. A. Bitar, and Y. Kerr, "Self-calibrated evaporation-based disaggregation of SMOS soil moisture: An evaluation study at $3 \mathrm{~km}$ and $100 \mathrm{~m}$ resolution in Catalunya, Spain," Remote Sens. Environ., vol. 130, pp. 25-38, Mar. 2013.

[22] J. Kim and T. S. Hogue, "Improving spatial soil moisture representation through integration of AMSR-E and MODIS products," IEEE Trans. Geosci. Remote Sens., vol. 50, no. 2, pp. 446-460, Feb. 2012.

[23] P. M. Atkinson, E. Pardo-Iguzquiza, and M. Chica-Olmo, "Downscaling cokriging for super-resolution mapping of continua in remotely sensed images," IEEE Trans. Geosci. Remote Sens., vol. 46, no. 2, pp. 573-580, Feb. 2008

[24] N.-W. Park, "Spatial downscaling of TRMM precipitation using geostatistics and fine scale environmental variables," Adv. Meteorol., vol. 2013, no. 11, pp. 187-190, 2013.

[25] A. W. Western, R. B. Grayson, and G. Blöschl, "Scaling of soil moisture: A hydrologic perspective," Апnи. Rev. Earth Planetary Sci., vol. 30, pp. 149-180, May 2002.

[26] H. Adab, K. D. Kanniah, K. Solaimani, and K. P. Tan, "Estimating atmospheric humidity using MODIS cloud-free data in a temperate humid region," in Proc. IEEE Geosci. Remote Sens. Symp. (IGARSS), Jul. 2013, pp. 1827-1830.

[27] Q. Wang, W. Shi, P. M. Atkinson, and Y. Zhao, "Downscaling MODIS images with area-to-point regression kriging," Remote Sens. Environ., vol. 166, pp. 191-204, Sep. 2015.

[28] Y. Ge, Y. Liang, J. Wang, Q. Zhao, and S. Liu, "Upscaling sensible heat fluxes with area-to-area regression kriging," IEEE Geosci. Remote Sens. Lett., vol. 12, no. 3, pp. 656-660, Mar. 2015.

[29] T. Hengl, G. B. M. Heuvelink, and D. G. Rossiter, "About regressionkriging: From equations to case studies," Comput. Geosci., vol. 33, no. 10, pp. 1301-1315, Oct. 2007.

[30] P. C. Kyriakidis, "A geostatistical framework for area-to-point spatial interpolation," Geograph. Anal., vol. 36, no. 3, pp. 259-289, Jul. 2004

[31] R. Kerry, P. Goovaerts, B. G. Rawlins, and B. P. Marchant, "Disaggregation of legacy soil data using area to point kriging for mapping soil organic carbon at the regional scale," Geoderma, vol. 170, pp. 347-358, Jan. 2012 
[32] L. Yongzhong, G. Yong, and W. Jianghao, "Review of geostatisticalbased downscaling," Remote Sens. Technol. Appl., vol. 30, no. 1, pp. 1-7, 2015.

[33] P. M. Atkinson, "Downscaling in remote sensing," Int. J. Appl. Earth Observ. Geoinf., vol. 22, no. 1, pp. 106-114, 2013.

[34] M. Hu et al., "Scaling flux tower observations of sensible heat flux using weighted area-to-area regression kriging," Atmosphere, vol. 6, no. 8, pp. 1032-1044, 2015.

[35] L. Poggio and A. Gimona, "Modelling high resolution RS data with the aid of coarse resolution data and ancillary data," Int. J. Appl. Earth Observ. Geoinf., vol. 23, no. 23, pp. 360-371, Aug. 2013.

[36] Q. Wang, W. Shi, P. M. Atkinson, and E. Pardo-Igúzquiza, "A new geostatistical solution to remote sensing image downscaling," IEEE Trans. Geosci. Remote Sens., vol. 54, no. 1, pp. 386-396, Jan. 2016.

[37] Q. Wang, W. Shi, Z. Li, and P. M. Atkinson, "Fusion of Sentinel2 images," Remote Sens. Environ., vol. 187, pp. 241-252, Dec. 2016.

[38] K. Yang, T. Koike, I. Kaihotsu, and J. Qin, "Validation of a dual-pass microwave land data assimilation system for estimating surface soil moisture in semiarid regions," J. Hydrometeorol., vol. 10, pp. 780-793, Jun. 2009

[39] A. S. Fotheringham, C. Brunsdon, and M. Charlton, Geographically Weighted Regression: The Analysis of Spatially Varying Relationships. Hoboken, NJ, USA: Wiley, 2003.

[40] P. Harris, A. S. Fotheringham, R. Crespo, and M. Charlton, "The use of geographically weighted regression for spatial prediction: An evaluation of models using simulated data sets," Math. Geosci., vol. 42, no. 6 , pp. 657-680, Aug. 2010.

[41] K. Imaoka, M. Kachi, M. Kasahara, N. Ito, K. Nakagawa, and T. Oki, "Instrument performance and calibration of AMSR-E and AMSR2," Int. Arch. Photogramm., Remote Sens. Spatial Inf. Sci., vol. 38, no. 8, pp. 13-18, 2010.

[42] X. Li et al., "Heihe watershed allied telemetry experimental research (HiWATER): Scientific objectives and experimental design," Bull. Amer. Meteorol. Soc., vol. 94, no. 8, pp. 1145-1160, 2013.

[43] B. Lu, P. Harris, M. Charlton, and C. Brunsdon, "The GWmodel $\mathrm{R}$ package: Further topics for exploring spatial heterogeneity using geographically weighted models," Geo-Spatial Inf. Sci., vol. 17, no. 2, pp. 85-101, 2014.

[44] Y. Leung, C.-L. Mei, and W.-X. Zhang, "Statistical tests for spatial nonstationarity based on the geographically weighted regression model," Environ. Planning A, vol. 32, pp. 9-32, Jan. 2000.

[45] P. Goovaerts, "Kriging and semivariogram deconvolution in the presence of irregular geographical units," Math. Geosci., vol. 40, no. 1, pp. 101-128, Jan. 2008

[46] R Core Team. (2013). R: A Language and Environment for Statistical Computing. $R$ Foundation for Statistical Computing, Vienna, Austria. [Online]. Available: http://www.R-project.org/

[47] O. Merlin et al., "Performance metrics for soil moisture downscaling methods: Application to DISPATCH data in central Morocco," Remote Sens., vol. 7, no. 4, pp. 3783-3807, 2015.

[48] N. Djamai, R. Magagi, K. Goïta, O. Merlin, Y. Kerr, and A. Roy, "A combination of DISPATCH downscaling algorithm with CLASS land surface scheme for soil moisture estimation at fine scale during cloudy days," Remote Sens. Environ., vol. 184, pp. 1-14, Oct. 2016.

[49] Y. Ge, J. H. Wang, G. B. M. Heuvelink, R. Jin, X. Li, and J. F. Wang, "Sampling design optimization of a wireless sensor network for monitoring ecohydrological processes in the Babao River basin, China," Int. J. Geograph. Inf. Sci., vol. 29, no. 1, pp. 92-110, 2015.

[50] R. M. Parinussa, T. R. H. Holmes, N. Wanders, W. A. Dorigo, and R. A. M. de Jeu, "A preliminary study toward consistent soil moisture from AMSR2," J. Hydrometeorol., vol. 16, pp. 932-947, Apr. 2015.

[51] E. G. Njoku, T. J. Jackson, V. Lakshmi, T. K. Chan, and S. V. Nghiem, "Soil moisture retrieval from AMSR-E," IEEE Trans. Geosci. Remote Sens., vol. 41, no. 2, pp. 215-229, Feb. 2003.

[52] Z. Wan, P. Wang, and X. Li, "Using MODIS land surface temperature and normalized difference vegetation index products for monitoring drought in the southern Great Plains, USA," Int. J. Remote Sens., vol. 25, no. 1, pp. 61-72, 2004.

[53] I. Sandholt, K. Rasmussen, and J. Andersen, "A simple interpretation of the surface temperature/vegetation index space for assessment of surface moisture status," Remote Sens. Environ., vol. 79, nos. 2-3, pp. 213-224, Feb. 2002.

[54] J. Peng, A. Loew, S. Zhang, J. Wang, and J. Niesel, "Spatial downscaling of satellite soil moisture data using a vegetation temperature condition index," IEEE Trans. Geosci. Remote Sens., vol. 54, no. 1, pp. 558-566, Jan. 2016
[55] K. Yang et al., "Auto-calibration system developed to assimilate AMSR-E data into a land surface model for estimating soil moisture and the surface energy budget," J. Meteorol. Soc. Jpn., Ser. II, vol. 85A, pp. 229-242, 2007

[56] H. Lievens et al., "SMOS soil moisture assimilation for improved hydrologic simulation in the Murray Darling Basin, Australia," Remote Sens. Environ., vol. 168, pp. 146-162, Oct. 2015.

[57] W. Wagner et al., "Evaluation of the agreement between the first global remotely sensed soil moisture data with model and precipitation data," J. Geophys. Res., Atmos., vol. 108, no. D19, pp. 1675-1702, 2003.

[58] W. T. Crow et al., "Upscaling sparse ground-based soil moisture observations for the validation of coarse-resolution satellite soil moisture products," Rev. Geophys., vol. 50, no. 2, pp. 3881-3888, 2012.

[59] M. H. Cosh et al., "The soil moisture active passive Marena, Oklahoma, in situ sensor testbed (SMAP-MOISST): Testbed design and evaluation of in situ sensors," Vadose Zone J., vol. 15, no. 4, pp. 1-11, 2016.

[60] J. Kang, R. Jin, X. Li, C. Ma, J. Qin, and Y. Zhang, "High spatiotemporal resolution mapping of soil moisture by integrating wireless sensor network observations and MODIS apparent thermal inertia in the Babao River Basin, China," Remote Sens. Environ., vol. 191, pp. 232-245, Mar. 2017.

[61] T. Hengl, "SoilGrids250m: Global gridded soil information based on machine learning," PLoS ONE, vol. 12, no. 2, p. e0169748, 2017.

[62] P. N. Truong, G. B. M. Heuvelink, and E. Pebesma, "Bayesian areato-point kriging using expert knowledge as informative priors," Int. J. Appl. Earth Observ. Geoinf., vol. 30, pp. 128-138, Aug. 2014.

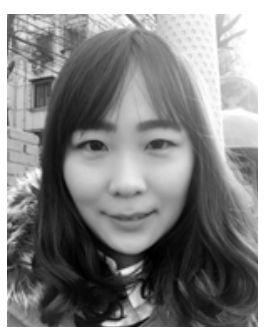

Yan Jin received the B.S. degree in information and computation science and the M.S. degree in applied mathematics from Chang'an University, Xi' an, China, in 2011 and 2014, respectively. She is currently pursuing the Ph.D. degree in cartography and geographical information system with the State Key Laboratory of Resources and Environmental Information System, Institute of Geographic Sciences and Natural Resources Research, Chinese Academy of Sciences, Beijing, China.

Her research interests include scale transformation, data fusion, geostatistics, and remote sensing applications.

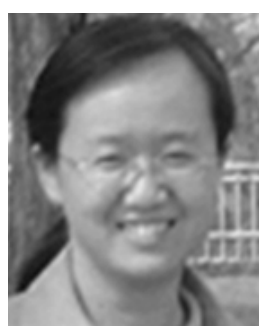

Yong Ge (M'14) received the Ph.D. degree in cartography and geographical information system from the Chinese Academy of Sciences (CAS), Beijing, China, in 2001.

She is currently a Professor with the State Key Laboratory of Resources and Environmental Information System, Institute of Geographic Sciences and Natural Resources Research, CAS. She has directed research in more than ten national projects. She has authored or co-authored over 100 scientific papers published in refereed journals, one book, and six chapters in books, has edited one book, and holds eight granted patents in improving the accuracy of information extraction from remotely sensed imagery. Her research interests include spatial data analysis and data quality assessment.

Dr. Ge is a Steering Committee Member of the International Spatial Accuracy Research Association and the Editorial Board of Spatial Statistics (Elsevier). She has been involved in the organization of several international conferences and workshops.

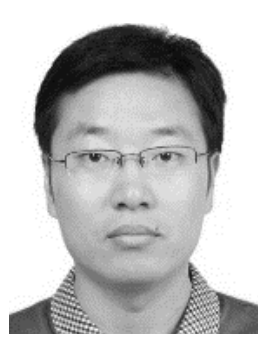

Jianghao Wang received the B.S. degree in geographical information system from Hohai University, Nanjing, China, in 2007, and the M.S. and Ph.D. degrees in cartography and geographical information system from the Chinese Academy of Sciences (CAS), Beijing, China, in 2010 and 2014, respectively.

$\mathrm{He}$ is currently an Assistant Professor with the State Key Laboratory of Resources and Environmental Information System, Institute of Geographic Sciences and Natural Resources Research, CAS. His research interests include the spatial statistics, remote sensing of environments, and urban studies. He has authored over 30 peer-reviewed journal articles in these fields. 


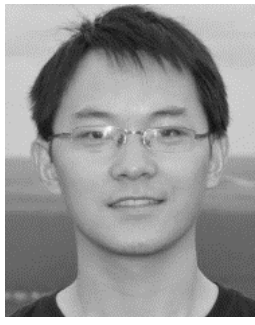

Yuehong Chen received the B.S. degree from Hohai University, Nanjing, China, in 2010, and the M.S. and $\mathrm{Ph} . \mathrm{D}$. degrees from the State Key Laboratory of Resources and Environmental Information System, Institute of Geographic Sciences and Natural Resources Research, Chinese Academy of Sciences, Beijing, China, in 2013 and 2016, respectively.

$\mathrm{He}$ is currently a Research Assistant with the School of Earth Sciences and Engineering, Hohai University. His research interests include remote sensing image processing and super resolution mapping.

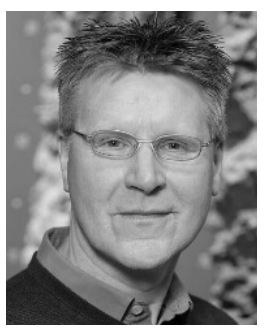

Gerard B. M. Heuvelink received the M.Sc. degree in applied mathematics from Twente Technical University, Enschede, The Netherlands, in 1987, and the $\mathrm{Ph} . \mathrm{D}$. degree in environmental sciences from Utrecht University, Utrecht, The Netherlands, in 1993.

He was an Assistant Professor with the University of Amsterdam, Amsterdam, The Netherlands, until 2003, when he accepted a dual appointment as Senior Researcher with the International Soil Reference and Information Centre (ISRIC) and an Associate Professor with Wageningen University, Wageningen, The Netherlands. In 2011, he changed his appointment at ISRIC - World Soil Information for a position as a Senior Researcher. Since 2011, he has been a Visiting Professor at the University of Chinese Academy of Sciences, Beijing, China. In 2017, he was appointed as a Special Professor of pedometrics and digital soil mapping at Wageningen University. He has authored or co-authored over 250 scientific publications on geostatistics, spatial uncertainty analysis, and pedometrics, about 110 of which appeared in peer-reviewed international journals.

Dr. Heuvelink is an Associate Editor of the European Journal of Soil Science and Spatial Statistics. He received the Richard Webster Medal from the Pedometrics Commission of the International Union of Soil Science in 2014.

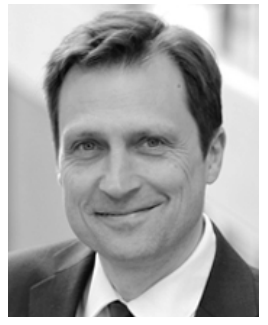

Peter M. Atkinson received the B.Sc. degree in geography from the University of Nottingham, Nottingham, U.K., in 1986, the Ph.D. degree from The University of Sheffield (NERC CASE award with Rothamsted Experimental Station), Sheffield, U.K., in 1990, and the MBA degree from the University of Southampton, Southampton, U.K., in 2012.

He was a Professor of geography at the University of Southampton (for 21 years; 13 years as a Full Professor), where he is currently a Visiting Professor. $\mathrm{He}$ is currently the Dean of the Faculty of Science and Technology, Lancaster University, Lancaster, U.K., and a Professor of spatial data science with the Lancaster Environment Centre, Lancaster. He is also a Visiting Professor with Queen's University Belfast, Belfast, U.K., and with the Chinese Academy of Sciences, Beijing, China. He has authored over 250 peer-reviewed articles in international scientific journals and around 50 refereed book chapters. He has also edited nine journal special issues and eight books. His research interests include remote sensing, geographical information science, and spatial (and space-time) statistics applied to a range of environmental science and socio-economic problems.

Prof. Atkinson is an Associate Editor of Computers and Geosciences and serves on the editorial boards of several journals including Geographical Analysis, Spatial Statistics, the International Journal of Applied Earth Observation and Geoinformation, and Environmental Informatics. He also serves on various international scientific committees. 